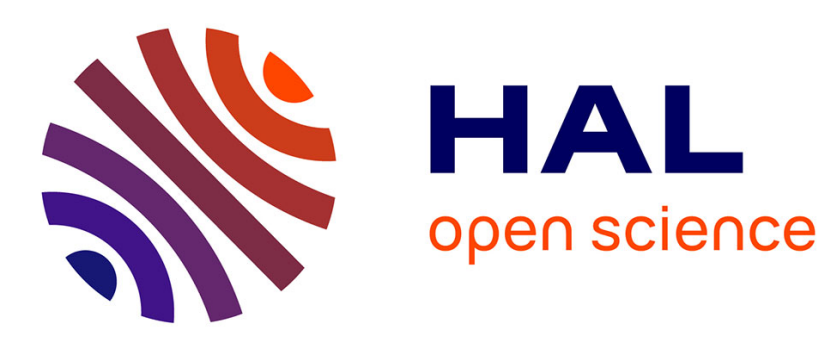

\title{
Once upon a time there was EIS
}

Claude Gabrielli

\section{To cite this version:}

Claude Gabrielli. Once upon a time there was EIS. Electrochimica Acta, 2020, 331, pp.135324. 10.1016/j.electacta.2019.135324 . hal-02430286

\section{HAL Id: hal-02430286 https://hal.science/hal-02430286}

Submitted on 7 Jan 2020

HAL is a multi-disciplinary open access archive for the deposit and dissemination of scientific research documents, whether they are published or not. The documents may come from teaching and research institutions in France or abroad, or from public or private research centers.
L'archive ouverte pluridisciplinaire HAL, est destinée au dépôt et à la diffusion de documents scientifiques de niveau recherche, publiés ou non, émanant des établissements d'enseignement et de recherche français ou étrangers, des laboratoires publics ou privés. 


\title{
Once upon a time there was EIS
}

\author{
Claude GABRIELLI \\ LISE - Laboratoire Interfaces et Systèmes Electrochimiques \\ Sorbonne Université - CNRS \\ 4 Place Jussieu \\ 75252 Paris - France \\ claude.gabrielli@gmail.com
}

\begin{abstract}
During the second half of the $19^{\text {th }}$ century, electrochemists began to measure the impedance of an electrode immersed in an electrolyte using alternating currents. At the turning of the 20th century some first models of the kinetics of the electrochemical reactions between an electrode and an electrolyte were published to explain the impedances achieved. They were particularly dealing with diffusion and adsorbed intermediates. However, in these times, experiments limited to the acoustical frequencies showed only a capacitance and a resistance. It is only at the end of the sixties in the $20^{\text {th }}$ century that the possibility to perform impedance measurements down to very low frequencies allows these models to be tested.
\end{abstract}

During the following years, thanks to the improvement of the measurement techniques towards low frequencies, with the help of new equipment, numerous electrochemical systems were investigated and various models were proposed. Therefore, at the end of the eighties it was decided to report on the advances of the electrochemical impedance spectroscopy (EIS) approach by organizing a meeting dedicated to this technique and its applications. So, the First International Symposium on the Electrochemical Impedance Spectroscopy was organized in June 1989 in Bombannes (France).

During the next thirty years many developments of EIS arose concerning various applications and techniques. Hence, new transfer functions based on frequency analysis of different quantities which control the electrochemical kinetics, local impedance measurements for non-homogeneous electrodes were 
derived to obtain rate constants and diffusion coefficients of interfacial phenomena.

\section{Introduction}

It is generally admitted that electrochemistry was discovered at the end of the $18^{\text {th }}$ century. However, hints of the possible use, a long time ago, of some electrochemical techniques were evoked anyway. Actually, some artefacts were found in excavations, in particular in the Middle East, which led some archaeologists to claim that some forms of electrochemistry were known 2000 years ago. In this way, the discovery of the so-called Baghdad (or Parthian) battery was interpreted as the ancestor of our modern battery [1], [2], [3]. Similarly, metal plating on funeral mascs for the Egyptians [4] or coins for the Romans [5] was then presumed to be carried out by electrolysis [6]. However, these assumptions were highly controversial as many peoples did not agree. Some argued against the possibility of the battery [7] and, so far, surface analysis of ancient plated metals with modern instruments showed that it was rather used mercury-based coating methods instead of electrolysis [8], [9]. Even the writings of Pline the elder were reinterpreted to demonstrate that he did not actually consider electroplating [10].

In any case, it was really at the end of the $18^{\text {th }}$ century that a modern scientific approach of electrochemistry began with the discovery of electricity and dc power sources by Galvani and Volta. Then, various steps can be stipulated:

-1800 - Nicholson and Carlisle found out water decomposition by electrolysis

-1800 - Ritter discovered the electroplating principle

-1832 - Faraday stated his two laws of electrochemistry

-1868 - Leclanché patented the zinc carbon cell

-1874 - Kohlrausch measured the conductivity of electrolytes

-1884 - Arrhenius showed that dissolved electrolytes dissociate into positive and negative ions

-1886 - Héroult and Hall invented, practically simultaneously in France and in USA, the production of aluminium by using electrolysis.

-1889 - Nernst gave the theory of electromotive force in a voltaic cell

-1909 - Millikan determined the charge of one electron 
-1922 - Heyrovsky devised the polarograph

Hence, the $19^{\text {th }}$ century was very fruitful for the development of electrochemical theory and techniques. So, to understand electrochemical mechanisms various techniques were proposed. Among all these techniques Electrochemical Impedance Spectroscopy (EIS) is based on sinewave analysis of stable electrochemical systems. This gives a unique "signature" of the investigated processes which has to be compared to a model, not always unique, inspired by the electrochemical theory to interpret the reactional mechanisms evolving at the metal-electrolyte interface. In this paper, the history of the EIS development is going to be followed. Only some steps in the theory of electrochemical impedance are mentioned in order to support the evolution of the technique. Among all the pioneering works elaborated during the $19^{\text {th }}$ century, Kohlrausch was the precursor of the Electrochemical Impedance Spectroscopy.

\section{The earliest ages of EIS}

\subsection{The Kohlrausch measurements}

Kohlrausch is famous for his law concerning electrolyte conductivity. However, to obtain the electrolytic solution conductance with a better accuracy he decided to measure the electrolyte resistance of a 2-electrode cell by means of alternating currents. He used a bridge, close to the Wheastone bridge which was proposed in 1843. Figure 1 shows the scheme of such a bridge, which will be used during almost 100 years to obtain the electrochemical impedance. It is balanced when

$$
V_{A}=V_{B}
$$

So, the current passing between $A$ and $B$ is zero $(I=0)$. In these conditions:

$$
Z_{1} Z_{3}=Z_{2} Z_{4}
$$

However, to perform such measurements, Kohlrausch needed a detector $D$ and a generator $G$.

\subsubsection{The detector for the Kohlrausch bridge}

A Weber bifilar dynamometer was used as a detector in the first Kohlrausch experiment published in 1869 [11]. This dynamometer, shown in Figure 2, was invented by Weber and the father of Kohlrausch in 1846 [12]. In this device, a coil was suspended by two wires within another coil. A current passing through 
one wire caused the first coil to rotate. A mirror detected the deviation. So, to balance the bridge, the dynamometer has to return at its idle state as the current passing through is zero.

Later, as soon as Bell invented the telephone in 1876, Kohlrausch and the followers used the telephone receiver as a detector. Sometime later an oscilloscope was used.

\subsubsection{The generator for the Kohlrausch bridge}

The device used to generate alternating currents was based on a magnet stuck on a rotating disk called by Kohlrausch a "sinus-induktor". In his first experiment published in 1869 , the rotation of the disk was produced by a siren put in motion by a blower. The frequency of this generator was estimated by measuring the sound of the siren thanks to organ pipes. However, Kohlrausch found this equipment not very accurate and to continue his experiments, he replaced it by a kind of clock machinery shown in Figure 3 [13]. Here, a weight was attached to a rope, a hand crank allowed the weight to be raised. When it was dropped, the rope provoked the movement of a gearbox which controlled the rotation of the disk. By changing the weight and the speed of the gearbox, it was possible to change the frequency of the signal given by this generator which was limited to the acoustical range.

Later, various devices were used by the experimentalists up to 1920 when the first electronic vacuum tube oscillators were introduced. The ancestor of our modern signal generators was commercially available only in 1928 manufactured by General Radio.

2.1.3 Measurement of the electrolyte resistance with an alternating current.

To obtain the conductance of an electrolyte, Kohlrausch began to measure the resistance of a 2-electrode cell, $C$, which was inserted in one branch of the bridge (Figure 4). However, to his surprise, to balance the bridge, he was obliged to add a capacity $C_{n}$ in series with the sought resistance $R_{n}$ [14]. He proposed that this parasitic capacitance was due to the polarization of the electrodes, so he called this capacity the "polarization capacitance". The phase shift introduced by the polarization capacitance was called $\Psi$. The couple $\left(C_{n}, \Psi\right)$ will be considered to characterize the interfacial behaviour of the electrodes immersed in an electrolyte during more than 60 years. 
2.2 The successors of the Kohlrausch pioneering work.

After Kohlrausch numerous researchers, mainly from the German school, carried out experiments to investigate the polarization capacitance: Herwig [15], Colley [16], and others. As an example, Wien [17] in 1896 changed the distance $l$ between the electrodes (Figure 5). He found that, whereas the cell capacitance was distance independent, the cell resistance value increased linearly with the electrode distance but did not cross the origin when the distance went to zero:

$$
R=k l+\Delta r
$$

So, Wien concluded that in addition to the resistance $k l$ related to the resistivity of the electrolyte, an extra resistance $\Delta r$ appeared, in addition to the polarization capacitance, which were related to the electrodes. He called this quantity the "polarization resistance".

He showed that for electrodes made of nickel, silver, platinum or mercury, the polarization resistance was inversely proportional to the electrode area, independent of the current density up to $105 \mathrm{~mA} / \mathrm{cm} 2$, and frequencyindependent between 64 and $256 \mathrm{~Hz}$; whereas, the polarisation capacitance was proportional to the electrode area, independent of the current density, and frequency independent."

As $\quad \Delta r C \omega=\tan \quad \Psi$

where $\omega=2 \pi f$ and $f$ is the frequency,

$\Psi$ was independent of the electrode area, current density, and frequency but it was dependent on the metal electrode and electrolyte

2.3 The Warburg theory

\subsubsection{The Neumann experiment}

In 1899 Elsa Neumann (who was the first physicist woman who got a doctorate in Germany), a pupil of Warburg, published a paper [18] which will be the basis of the Warburg theory. She investigated the impedance between metallic electrodes in a solution of a metallic salt in low concentration and a second electrolyte with the same anion in larger concentration.

She found that for mercury and silver and for frequencies between 130 and $400 \mathrm{~Hz}$ 


$$
C \sqrt{\omega}=\text { a constant }, \quad \Delta r \sqrt{\omega}=\text { a constant, } \text { so } \omega C \Delta r \sim 1
$$

She studied the influence on $C$ and $\Delta r$ of the concentration of the salt and the amplitude of the current at $130 \mathrm{~Hz}$ where non-linear effects appeared (Figure $6)$.

\subsubsection{The Warburg model}

In 1901 Warburg published his famous paper to propose an explanation for the experimental data observed [19]. He considered an alternating current

$$
j=\operatorname{asin}[\omega t]
$$

and an electromotive force

$$
p=\frac{a}{C \omega} \sin \left[\omega t-\left(\frac{\pi}{2}-\Psi\right)\right]
$$

where $C$ is the polarization capacity

By considering the Fick law for the diffusion

$$
\frac{\partial \gamma}{\partial t}=D \frac{\partial^{2} \gamma}{\partial z^{2}}
$$

he wrote

$$
\frac{j}{q} \frac{Ц A}{107,9}=g \sin \omega t=-D\left(\frac{\partial \gamma}{\partial z}\right)_{z=0}+\frac{\partial \Gamma}{\partial t}
$$

where $\gamma$ and $\Gamma$ are the concentrations of the diffusing species in the solution and on the electrode surface, $A$ is the electrochemical equivalent of the electrode metal, Ц is the electrochemical equivalent of hydrogen, $D$ the diffusion coefficient, $j$ the current density, $\omega=2 \pi f$ the angular frequency, and $q$ the electrode area. Hence

$$
C=\frac{107,9 q}{A Ц} \frac{1}{\left(\frac{\partial e}{\partial \gamma}\right)_{\gamma=\gamma_{0}}} \frac{\sqrt{\frac{D}{2 \omega}}}{\sin \psi} \quad \tan \Psi=\frac{1}{1+\mu \sqrt{\frac{2 \omega}{D}}}
$$

where $\quad \frac{\partial \Gamma}{\partial t}=\frac{\partial \Gamma}{\partial \gamma} \frac{\partial \gamma}{\partial t}=\mu \frac{\partial \gamma}{\partial t} \quad \frac{\partial e}{\partial \gamma}=\frac{e-e_{0}}{\gamma-\gamma_{0}}=\frac{p}{\gamma-\gamma_{0}}$

Warburg considered two limiting cases:

1) $\mu \sqrt{2 \omega / D} \gg 1 \quad$ then 


$$
\begin{aligned}
& \text { - } \tan \Psi=\frac{1}{\mu \sqrt{\frac{2 \omega}{D}}} \quad \text { consequently } \Psi=0 \\
& \text { - } C=\frac{107,9 q}{A Ц} \frac{1}{\left(\frac{\partial e}{\partial \gamma}\right)_{\gamma=\gamma_{0}}}
\end{aligned}
$$

This is the case investigated by Kohlrausch for " non-polarizable » electrodes

2) $\mu \sqrt{2 \omega / D} \ll 1 \quad$ then

$$
\begin{aligned}
& \tan \Psi=1, \quad \sin \Psi=\frac{1}{\sqrt{2}}, \quad \text { consequently } \quad \Psi=\frac{\pi}{4} \\
& \text { - } C=\frac{107,9 q}{A Ц} \frac{1}{\left(\frac{\partial e}{\partial \gamma}\right)_{\gamma=\gamma_{0}}} \sqrt{\frac{D}{\omega}}
\end{aligned}
$$

This is the case investigated by Neumann for "polarizable electrodes" whose behaviour in $\sqrt{\omega}$ will be known up to now as the "Warburg impedance".

2.4 Changes in the views about the capacitive behaviour of the electrodes during the 50 years after the Kohlrausch experiment.

Before Kohlrausch, Varley was the first to demonstrate the condenser effect of the electromotive force in an electrolytic cell in a patent in 1860 [20]. Then, Kolhrausch had proved the existence of a capacity at the surface of an electrode placed in an electrolytic solution. Warburg first attempted an explanation of the occurrence of this quantity in terms of the transport of electrolyte.

However, numerous controversial discussions occurred between electrochemists up to the 1920's due to the narrow frequency bandwidth explored and the various metals of the electrodes and electrolytic solutions tested in their experiments. These discussions concerned especially the frequency dependence of the polarization capacity either following $\omega^{-m}$ or $A+B \omega^{-m}$ where $m$ may vary from 0 to 1 [21], [22]. Nevertheless, an experiment carried out in $\mathrm{Ag} / \mathrm{AgNO}_{3}$ by Banerji [23], where the capacity was measured between 170 and $7500 \mathrm{~Hz}$, showed that the Warburg theory seems to be valid only in the low frequency range. Observations in the high-frequency range were attributed to another capacitive phenomenon related to the double layer (Figure 7).

2.5 In the 1930 's, two attractive papers, but forgot by the followers, were published. 
2.5.1 N. Thon in 1934 [24] considered that the "complex resistance" of an electrode immersed in an electrolyte can be represented by an electrolyte resistance $R$ in series with a capacity $C$ and a resistance $r$ in parallel due to the electrodes. So, he wrote this quantity under the complex form:

$$
R+\frac{r}{1+\omega^{2} r^{2} C^{2}}-i \frac{\omega r^{2} C}{1+\omega^{2} r^{2} C^{2}}
$$

where

$$
i=\sqrt{-1}
$$

2.5.2 Murdock and Zimmerman in 1936 published a paper [25] about the measurement of the "polarization impedance" at low frequencies. The measurements in the acoustic frequency range was made by using a classical bridge but the innovation was to use the equipment described in Figure 8a to carry out measurements of the impedance of the 2-electrodes cell at very low frequencies i.e. down to $0.05 \mathrm{~Hz}$. The low frequency measuring potential was generated by means of the device $T$ which is a $\mathrm{Cu}-\mathrm{CuSO}_{4}-\mathrm{Cu}$ cell with a current of uniform density in the solution. This current was modulated by a rotating vertical shaft which allowed an alternating potential of the desired amplitude to be generated and applied to the electrochemical cell $C$ that was being studied.

The current which crossed the cell passed through the string galvanometer $S$.G. and was recorded as a function of time on a moving photographic plate to determine its frequency and amplitude and the phase difference between the current and the impressed electromotive force.

The impedance was measured on $\mathrm{Pt}$ immersed in $0.25 \mathrm{~N} \mathrm{H}_{2} \mathrm{SO}_{4}$ and its real part and imaginary part were plotted in Figure 8b. However, the small crosses, which indicate the measured impedance in the low frequency range, had, according to the authors, a rather bad accuracy.

Thus, these authors attempted for the first time to measure the electrochemical impedance at low frequency down to $0.05 \mathrm{~Hz}$ and to plot the real and imaginary parts vs frequency. These pioneering ideas were rediscovered only almost 30 years later.

\section{The gestation of EIS}

During the next three decades the tools to create EIS, both on the experimental and theoretical points of view, were devised.

\subsection{The 1940's.}


This period saw the progress in the equipment (potentiostat, rotating disc electrode) and the interpretation of the data through the equivalent circuit.

3.1.1. So far, only 2-electrode cells were used to examine the electrode behaviour, but in these conditions, the two electrodes were tested in series. In 1942 Hickling [26] proposed to polarize a 3-electrode cell by using the electronic circuit depicted in Figure 9 made with vacuum tubes. He called this device a "potentiostat". So, the investigated electrode, called the working electrode, was separately polarized with respect to a reference electrode where no current passed through.

3.1.2. In 1942, B. Levich, a member of the Frumkin laboratory in Moscow (U.S.S.R.), proposed to use a rotating disc electrode (RDE) in 3-electrode cells [27]. A metallic cylinder was embedded in an insulator, the working electrode was then its cross section (Figure 10a). When it was rotated, the electrolyte was sucked up to the electrode. The RDE is one of the few convective electrode systems for which the hydrodynamic equations and the convective-diffusion equation have been solved rigorously for the steady-state. He showed that the rotating disc system provides an uniformly accessible electrode, i.e. at the interface, the flux and the concentration of a species produced or consumed on the electrode are independent of the position on the electrode surface. The convective diffusion imposes a finite thickness of the diffusion layer $\delta_{N}$ :

$$
\delta_{N}=\frac{1.61(D / v)^{\frac{1}{3}}}{(v / \Omega)^{\frac{1}{2}}}
$$

where $D$ is the diffusion coefficient, $v$ the viscosity of the solution, and $\Omega$ the rotation speed, or angular velocity, of the disc electrode.

This leads to a limiting current $i_{L D}$ :

$$
i_{L D}=0.62 n_{D} F \pi r_{1}^{2} c D^{\frac{2}{3}} v^{-\frac{1}{6}} \Omega^{\frac{1}{2}}
$$

where $n_{D} F$ is the number of coulombs flowing through the electrode per mole of the reactant of concentration $c$, and $r_{1}$ is the radius of the disc electrode.

As an example, Figure 10b shows the current-voltage curve of platinum in $10^{-3} \mathrm{M} \mathrm{Fe}(\mathrm{CN})_{6}^{3-}$ for rotation speeds of the electrode ranging from 1600 to $10000 \mathrm{rpm}$. As the theory predicts, the limiting current increases following $\sqrt{\Omega}$.

This technique was not largely used during the first following twenty years as the Levich paper was published in Russian and also because the Russian researchers could leave the U.S.S.R. in exceptionally rare cases during this period. 
It was discovered abroad only when Levich published his famous book [28] in English.

3.1.3. In 1947, Randles published a paper [29] which described a model where an electrochemical reaction is limited by diffusion in a layer of infinite thickness. So, he considered an electron transfer with rate constant $k$ :

$$
M \leftrightarrow M^{n+}+n e
$$

Moreover, he supposed that the diffusion of $M^{n+}$ was controlled by the Fick law:

$$
\frac{\partial C}{\partial t}=D \frac{\partial^{2} C}{\partial z^{2}}
$$

with the following boundary conditions:

$$
\begin{array}{ll}
\text { at } z=0 & i=-n F A D\left(\frac{\partial C}{\partial z}\right)_{z=0} \\
\text { at } z=\infty & c=c_{0}
\end{array}
$$

Hence the current vector $I$ leads to a voltage vector with a phase shift $\Psi$ :

$$
\frac{I}{V}=\frac{1}{R_{r}} \cos \Psi
$$

and

$$
\omega C_{r} R_{r}=\cot \Psi=1+\frac{1}{k} \sqrt{\frac{\omega D}{2}}
$$

Therefore, the electrode impedance corresponds to a capacitance $C_{r}$ and a resistance in series $R_{r}$ :

$$
C_{r}=\frac{n^{2} F^{2} A C}{R T} \sqrt{\frac{D}{2 \omega}} \quad \text { and } \quad R_{r}=\frac{R T}{n^{2} F^{2} A C}\left(\sqrt{\frac{2}{\omega D}}+\frac{1}{k}\right)
$$

So, he has proposed to represent the electrochemical impedance by the "Randles equivalent circuit" shown in Figure 11a where $R_{e}$ is the electrolyte resistance and $C_{d l}$ the double layer capacity. However, this Randles equivalent circuit depends on $C_{r}$ and $R_{r}$ which are frequency dependent.

On the other hand, as the electrochemical impedance related to $C_{r}$ and $R_{r}$ is equal to

$$
Z(\omega)=R_{r}+\frac{1}{j \omega C_{r}}
$$

$$
Z(\omega)=\frac{R T}{n^{2} F^{2} A C k}+\frac{R T}{n^{2} F^{2} A C} \sqrt{\frac{2}{\omega D}}+\frac{R T}{j \omega F^{2} A C} \sqrt{\frac{2 \omega}{D}}
$$

so

$$
Z(\omega)=R_{t}+W(\omega)
$$


where $\quad R_{t}=\frac{R T}{n^{2} F^{2} A C k} \quad$ is the transfer resistance, and $\quad W(\omega)=\frac{R T}{n^{2} F^{2} A C k}(1-j) \sqrt{\frac{2}{\omega D}}$ is the Warburg impedance.

Therefore, the equivalent circuit of the impedance is rather represented nowadays by the scheme depicted in Figure $11 \mathrm{~b}$.

The Randles model is quite close to the model proposed by Warburg, almost fifty years before, but surprisingly the name of the German pioneer did not appear in the Randles paper.

\subsection{The 1950 's.}

This period was rather devoted to modelling of electrochemical reactions limited by diffusion or not to explain experimental data plotted in the complex plane.

3.2.1. In 1955 Gerischer and Mehl proposed a model of electrochemical reactions with an adsorbed intermediate which will be the basis of the modern models of the kinetic behaviour of many electrode-electrolyte interfaces [30]. They considered the global reaction of hydrogen evolution which occurs in two steps:

Volmer reaction:

$$
H_{\text {solv }}^{+}+e^{-} \rightarrow H_{a d s}
$$

Horiuti (or Heyrovsky) reaction: where $H_{a d s}$ is an adsorbed intermediate.

The current densities $j_{V}$ and $j_{H}$ of these two elementary reactions are equal to:

$$
\begin{aligned}
& j_{V}=(1-\theta) j_{V, 0} e^{-\frac{F \beta_{V}}{R T} \eta} \\
& j_{H}=\theta j_{H, 0} e^{-\frac{F \beta_{H}}{R T} \eta}
\end{aligned}
$$

and

where $\theta$ is the coverage rate of the surface of the adsorbed hydrogen $H_{a d s}$. For a sine wave voltage of low amplitude and frequency $f=\frac{\omega}{2 \pi}$,

$$
\Delta \eta=K e^{i \omega t} \quad \text { where } i=\sqrt{-1}
$$

they calculated the expression of an impedance such as: 


$$
\frac{1}{Z_{F}}=\frac{1}{R_{t}}+\frac{a}{b+i C_{H} \omega}
$$

where $C_{H}$ is the adsorption capacity and $R_{t}$ is the transfer resistance such as:

$$
\frac{1}{R_{t}}=\frac{F}{R T}\left(\beta_{V} j_{V}+\beta_{H} j_{H}\right)
$$

and the quantities

$$
\text { and } \quad \begin{aligned}
a & =\frac{F}{R T}\left(j_{H}-j_{V}\right)\left(\beta_{H} j_{H}-\beta_{V} j_{V}\right), \\
b & =j_{V}+j_{H}+2 \theta j_{T}
\end{aligned}
$$

Thus, an important conclusion was predicted by this model concerning the imaginary part of the electrochemical impedance which will be capacitive if $a>$ 0 or inductive if $a<0$.

3.2.2. In 1959 Llopis et al. published a model of an electrochemical reaction of the Gerischer type limited by diffusion. [31]. The reaction scheme is described in Figure 12. According to the Gerischer modelling the total rate of desorption is equal to:

$$
v_{0}=k_{0}^{d} \theta_{0}-k_{0}^{S}\left(1-\theta_{0}-\theta_{r}\right) c_{0}
$$

together with

$$
\kappa \frac{d \theta_{0}}{d t}=-J-v_{0}
$$

where $\theta_{0}$ and $\theta_{r}$ are the coverage rates of the oxidized and reduced species.

The diffusion limitation follows the Fick law: $\quad \frac{\partial c_{0}}{\partial t}=D \frac{\partial^{2} c_{0}}{\partial z^{2}}$

with boundary conditions: at $z=0 D\left(\frac{\partial c_{0}}{\partial z}\right)_{z=0}=-v_{0}$ and at $\mathrm{z}=\infty \quad c_{0}=c_{0}^{0}$

So, they calculated an impedance such as:

$$
Z_{F}=\frac{R T}{n^{2} F^{2}}\left\{\frac{1}{J_{0}}+\left(\frac{1}{\theta_{0}^{0}}+\frac{1}{\theta_{r}^{0}}\right) \frac{1+k^{s} \beta(1-i)}{k^{d}+\kappa \omega i\left[1+k^{s} \beta(1-i)\right]}\right\}
$$

where $\quad \beta=\frac{1-\theta_{0}-\theta_{r}}{\sqrt{2 \omega D}}$ then

In the case $j=0$ and if the adsorption process had no effect $k^{s} / k^{d} \rightarrow 0$,

$$
Z_{F}=\frac{R T}{n^{2} F^{2}}\left[\frac{1}{J_{0}}+\frac{1-i}{\sqrt{2 \omega D}}\left(\frac{1}{c_{0}^{0}}+\frac{1}{c_{r}^{0}}\right)\right]
$$


which is the same result as the Randles one for a slow electron transfer limited by the reactant diffusion. $Z_{F}$ is still the sum of a transfer resistance and a Warburg impedance.

During this decade several kinetic models of electrochemical impedances were derived, e.g. by Grahame [32], to explain the polarization phenomena of an electrode immersed in an electrolyte. In addition, still using a bridge, but thanks to improvements of the measurement equipment (sinusoidal signal generator, oscilloscope or signal analyser for the detector) electrochemical impedances were measured in complicated experimental conditions. As examples, Bockris and Conway determined the impedance at solid electrodes during the electrodeposition of copper [33] and Laitinen and Osteryoung in molten lithium chloride -potassium chloride [34].

3.2.3. In 1960, electrochemists began to plot the electrochemical impedance in the complex plane (or Argand diagram). As these quantities were found, so far, only capacitive as they were measured in the acoustic frequency range, it was considered more convenient to plot the impedance in the first quadrant of the complex plane, and then to plot the impedance under the form:

$$
Z=Z^{\prime}-i Z^{\prime \prime}
$$

So, Sluyters [35] plotted the impedances, measured thanks to a bridge between $20 \mathrm{~Hz}$ and $20 \mathrm{kHz}$, for a diffusion limited process (Figure 13a) and for a reaction limited process (Figure $13 \mathrm{~b}$ ).

In the same way, Epelboin published a paper relative to the impedance of an anode of aluminium in phosphoric acid during electrochemical polishing [36]. It was the first time where an inductive behaviour was demonstrated in electrochemistry (Figure 14).

\subsection{The 1960 's.}

During this period impedance measurement in a large frequency range was developed together with models dealing with electrochemical processes in porous media or in finite diffusion layer. This completed the birth of EIS.

3.3.1. In 1963 De Levie [37], [38] proposed to model the impedance of a porous electrode by considering an ensemble of theoretical pores of uniform cross-section in an electrode material with no resistance and homogeneously filled 
with electrolyte. Hence, he considered an equivalent model shown in Figure 15. So, each pore was represented by a transmission line with a resistance $R$ of the electrolyte within the pore and an impedance $Z$ of the internal pore interface at a distance $z$ from the mouth of the pore. Therefore, the local potential $e$ and the local current $i$ are equal to:

$$
\begin{array}{lll}
d e=-i R d z & \text { so } & \frac{d e}{d z}+i R=0 \\
d i=-\frac{e}{Z} d z & \text { so } & \frac{d i}{d z}+\frac{e}{Z}=0
\end{array}
$$

On combining the previous equations, he got:

$$
\frac{d^{2} i}{d z^{2}}-\frac{R}{Z} i=0
$$

and

$$
\frac{d^{2} e}{d z^{2}}-\frac{R}{Z} e=0
$$

The solution of these equations with appropriate boundary conditions for shallow pores of depth $l$ gives the impedance of the porous electrode:

$$
Z_{p}=\sqrt{Z R} \operatorname{cotanh} l \sqrt{\frac{R}{Z}}
$$

Other peoples have proposed models based on partial equations to calculate the impedance of porous electrodes [39]

3.3.2. In 1964 Drossbach proposed a model of an electron transfer limited by the diffusion in a layer of finite thickness, often called Nernst diffusion layer [40].

So, the diffusion is governed by the Fick law: $\frac{\partial C}{\partial t}=D \frac{\partial^{2} C}{\partial z^{2}}$

with the boundary conditions in a diffusion layer of thickness $\delta_{N}$ :

$$
\begin{array}{ll}
\text { at } \mathrm{z}<\delta_{N} \quad: \quad & c(\mathrm{z})=c(0)+\left(c_{0}-c(0)\right) \frac{\mathrm{z}}{\delta_{N}} \\
\text { at } \mathrm{z} \geq \delta_{N} \quad: \quad & c=c_{0}
\end{array}
$$

Therefore, the impedance is equal to:

$$
Z(\omega)=\frac{R T \gamma(1-j)}{n F c \sqrt{2 D \omega}} \tanh \left(\delta_{N} \sqrt{\frac{j \omega}{D}}\right)
$$

which was plotted by Drossbach in the complex plane and reproduced in Figure 16. 
Such an electron transfer limited by diffusion in a layer of finite thickness, which is very useful for modelling a process evolving on a rotating disc electrode, was already introduced by Llopis and Colom in 1956 [41] in a complex model of a reaction mechanism with an adsorbed intermediate.

However, the Nernst hypothesis which led to the analytic solution given by Drossbach is only approximative. Much later, an exact solution was obtained numerically by using the convective diffusion equation [42]:

$$
\frac{\partial c}{\partial t}+v_{y} \frac{\partial c}{\partial y}-D \frac{\partial^{2} c}{\partial y^{2}}=0
$$

with the following boundary conditions:

$$
\begin{array}{lll}
c \rightarrow c(\infty) & \text { for } & y \rightarrow \infty \\
c=c(0) & \text { for } & y=0
\end{array}
$$

where $v_{y}$ is the speed of the solution along the y axis.

This numerical approach shows that the concentration profile corresponding to the Nernst hypothesis differs from the correct one at a distance close to the thickness of the Nernst layer, but the two profiles superimpose close to the electrode.

Concerning the convective diffusion impedance, this approach shows that if the Schmidt number, $S_{c}=\frac{v}{D}$, where $v$ is the viscosity and $D$ the diffusion coefficient, is infinitely large, it is rather close to the impedance found in the Nernst hypothesis. When the Schmidt number is lower, like in real electrolytes, the difference is higher.

In parallel to the classical modelling based on differential equations, Newman investigated the influence of the current distribution on the electrode surface on the electrochemical impedance [43]. This partly explains the "depressed" semi-circle often found experimentally.

3.3.3. In 1966 in the Epelboin laboratory in Paris a wideband potentiostat (Figure 17a) which allowed dc and ac to be added in a large frequency range was devised to polarize 3-electrode cells [44]. By using such an equipment and an electronic impedance meter it was possible to measure the impedance diagram depicted in Figure 17b. The measurement was performed between $15 \mathrm{~Hz}$ and $30 \mathrm{kHz}$. The impedance was plotted in the complex plane with the same unit on the real and imaginary parts. Here, it was certain that the frequency range of interest was completely explored as the impedance for the highest frequency was 
equal to the electrolyte resistance and the impedance for the lowest frequency was equal to the inverse of the slope of the current -voltage curve:

$$
Z(\infty)=R_{e} \quad Z(0)=\frac{1}{d I / d V}
$$

3.3.4. In 1967 Keddam [45] began to measure the electrochemical impedance in a very large frequency range. The $3 \mathrm{~Hz}-150 \mathrm{kHz}$ domain was analysed by using an electronic impedance meter, the $0.1 \mathrm{~Hz}-10 \mathrm{~Hz}$ was obtained by using Lissajous figures read on a memory oscilloscope and for frequency lower than $0.1 \mathrm{~Hz}$ current and voltage were registered on a $\mathrm{X}-\mathrm{Y}$ recorder from which amplitude and phase of the impedance were calculated.

By using these techniques, for the dissolution of iron in sulphuric medium, he was able to compare his experimental data obtained at various potentials (Figure 18a) with the impedance calculated for the reaction mechanism:

$$
\begin{aligned}
& K_{1} \\
& \mathrm{Fe}+\mathrm{OH}^{-} \underset{K_{1}^{\prime}}{\rightleftharpoons}[\mathrm{FeOH}]_{\mathrm{ads}}+\mathrm{e} \\
& K_{2} \\
& {[\mathrm{FeOH}]_{\mathrm{ads}} \rightarrow[\mathrm{FeOH}]^{+}+\mathrm{e}} \\
& {[\mathrm{FeOH}]^{+}+\mathrm{H}^{+} \rightleftharpoons \mathrm{Fe}^{2+}+\mathrm{H}_{2} \mathrm{O} \text {. }}
\end{aligned}
$$

For this mechanism of the Gerischer type, where iron is dissolved through an adsorbed intermediate $[\mathrm{FeOH}]_{a d s}$, he was able to derive the form of the faradaic impedance, $Z_{f}(\omega)$ such as:

$$
\frac{1}{Z_{f}(\omega)}=\frac{F K_{1}\left[O H^{-}\right] K_{2} \beta}{K_{1}\left[O H^{-}\right]+K_{2} \beta}\left[b_{1}+b_{2}+\frac{\left(K_{2} \beta-K_{1}\left[O H^{-}\right]\right)\left(b_{1}-b_{2}\right)}{j \omega \beta+K_{1}\left[O H^{-}\right]+K_{2} \beta}\right]
$$

where $K_{i}=K_{i 0} e^{b_{i} V}$

Depending on the sign of the term $b_{1}-b_{2}, Z_{f}(\omega)$ is inductive or capacitive depending on the potential through the $K_{i}$ (Figure 18b) [46], [47].

Similarly, the diffusion impedance on a rotating disc electrode was investigated between 0.15 and $180 \mathrm{~Hz}$ at various diffusion limiting currents (Figure 19) and compared with the Drossbach model for a diffusion in a layer of finite thickness $\delta_{N}[48]$ (see $Z(\omega)$ expression and plot in §3.3.2) 


\section{The growth of EIS}

At the beginning of the 1970's new advances in electronics boosted the development of the electrochemical impedance measurements. Namely, the operational amplifiers and the transfer function analysers allowed impedance measurements to be performed in a very large frequency range with a good accuracy.

4.1. The operational amplifiers (Figure 20a) are two voltage input devices: inverting $E_{-}$and non-inverting $E_{+}$which inverts and non-inverts the voltage inputs. They are characterized by a very large input impedance $R_{e}$ between the two inputs, a low output impedance $R_{S}$ and a large gain $A$. They are wideband devices able to drive frequencies between dc and, in the 70's some $10 \mathrm{kHz}$ [49], and nowadays two orders of magnitude higher. Their high gain imposes to use feedback. As an example, Figure 20b shows a simple circuit with a feedback loop which describes a simple wideband potentiostatic circuit $\left(V_{R}=E\right)$.

\subsection{The transfer function analyser}

The transfer function analysers were manufactured for aeronautics and various servomechanisms tests. They are able to analyse system responses to very low frequencies down to $10^{-5} \mathrm{~Hz}$. The first one, Solartron JM1600, was limited to a few hundreds of Hertz in the high frequency range but rapidly other devices, e.g. Schlumberger 1174, were able to go up to $1 \mathrm{MHz}$.

The principle is described on Figure 21a [50]. An input voltage $x(t)=$ $X_{0} \sin [\omega t]$ is sent to a system under test having a transfer function $K(\omega) e^{j \varphi(\omega)}$. The output $S(t)$ is equal to the sum of the fundamental term, the harmonic terms and the noise $n(t)$ :

$S(t)=X_{0} K(\omega) \sin [\omega t+\varphi(\omega)]+\sum_{m} A_{m} \sin \left[m \omega t-\varphi_{m}\right]+n(t)$

The analyser carries out two multiplications, one by the input signal and another one by a signal in quadrature, and then an integration so:

$$
\begin{aligned}
& \left.\frac{1}{T} \int_{0}^{T} S(t) \sin [\omega t] d t=X_{0} K(\omega) \cos \mid \varphi(\omega)\right]=X_{0} \operatorname{Re}[K(\omega)] \\
& \frac{1}{T} \int_{0}^{T} S(t) \cos [\omega t] d t=X_{0} K(\omega) \sin [\varphi(\omega)]=X_{0} \operatorname{Im}[K(\omega)]
\end{aligned}
$$


where $T$ is equal of a number of periods of the analysing sinusoidal signal.

So, the real $\operatorname{Re}[K(\omega)]$ and imaginary $\operatorname{Im}[K(\omega)]$ parts of the transfer function of the tested system are directly obtained.

Figure $21 \mathrm{~b}$ shows an example of the whole potentiostatic equipment showing the recording of the experimental data.

\subsection{Dissolution-passivation of iron in sulfuric medium [51], [52].}

By using these new equipments, rather complicated processes could be investigated. The current-voltage curve of a rotating disc iron electrode in a sulfuric acid medium, obtained thanks to a negative impedance regulation, is plotted in Figure 22a. The domain of the passivation is characterized by a multisteady state system where three currents corresponds to one potential. When the electrode is polarized on the intermediate branch it is non-uniformly attacked on a ring (Figure 22b). Hence, the current density-voltage curve has the form depicted on Figure 22c.

Concerning the electrochemical impedance (Figure 23), diagram (A) was obtained for potential between A and B on Figure 22c, where the current densityvoltage curve has a negative slope which corresponds to a negative value of the low frequency limit of the impedance. Diagram (B) was obtained for potentials ranging from $\mathrm{B}$ to $\mathrm{B}$ ' in Figure $22 \mathrm{c}$ where the slope of the current density-voltage curve measurements was positive and a positive value of the low frequency limit of the impedance. Diagram (C) was obtained for potentials between $\mathrm{C}$ and C' on Figure 22c where the slope is negative.

Regarding the reaction mechanism which may interpret the experimental data, Figure 24 gives the current-voltage curves for various rotation speeds of the iron electrode and the electrochemical impedance calculated from this reactional model at various potentials. It was based on the coupling of dissolution and passivation reactions by diffusion [53], [54].

\section{Development of EIS}

With this new type of equipment, easier to use, more accurate and less timeconsuming, EIS spreads all around the world. So, papers from Germany [55], Great Britain [56], USA [57], Brazil [58], Australia [59], or Japan [60] and more were published. Hence, Michel Keddam, Digby Macdonald and Claude Gabrielli decided to gather the users of this technique whatever their topic of interest. Then, 
the $1^{\text {st }}$ meeting devoted to EIS was organized in Bombannes (France) thirty years ago in June 1989. 250 attendants, with practically all the pioneers of the technique were assembled.

This meeting was renewed every 3 years all around the world up to the last one in June 2019 in Lège-Cap-Ferret (France).

During the 30 years spent after this first meeting many developments of EIS occurred. It was proposed to decrease the measurement time by applying all the frequencies simultaneously. As an example, Smith and then Popkirov proposed to use odd random phase sinusoidal signals to investigate timedependent systems [61], [62]. Similarly, non-stationary impedance analysis was used to test the charge of batteries during discharging by Stoynov [63]. New criteria were suggested to check the validity of the measured data, in particular by using Kramers-Kronig relationships [64], [65]

Extra advancements of EIS were attempted. Firstly, multi transfer function analysis between input quantities $(\mathrm{E}, \Omega, \mathrm{T}, \mathrm{P} \ldots$ ) and output quantities (I, mass, optics....) of the electrochemical system [66]. For example, ac-electrogravimetry [67], [68] $\frac{\Delta m}{\Delta E}$, which gives the response of the electrode mass measured by means of a fast quartz crystal microbalance to a potential perturbation or electrohydrodynamic impedance, [69], [70] $\frac{\Delta I}{\Delta \Omega}$, which gives the response of the current to a perturbation of the speed of the rotating disc electrode.

The classical impedance measurements give information on the electrode kinetics averaged on the whole surface. However, it is often necessary to obtain local information when the electrode reactivity is non-uniform. So, various techniques of local impedance measurements (LEIS) were proposed. Firstly, Isaacs used a bi-electrode to measure simultaneously the ac local potential with one electrode and the ohmic drop, and hence the ac local current, between the two microelectrodes [71]. Later Keddam used a scanning vibrating electrode technique (SVET) to determine the same quantities [72]. Afterwards, theoretical and experimental comparison of local and global impedances was achieved by using numerical calculations. It was shown that local impedances depend not only on the structure of the electrode but also on the geometrical position on the surface due to geometry-induced current and potential distribution at both high and low frequencies [73], [74].

The last meeting on EIS in Lège-Cap-Ferret has shown that many new advances are being developed to understand the kinetics of interfacial reactions for more and more complicated electrode-electrolyte systems. 


\section{Acknowledgements.}

I thank the organizer of the $11^{\text {th }}$ meeting on EIS in Lège-Cap-Ferret (June 2019), Dr Vincent Vivier, for inviting me to give the introductory lecture of the conference which is the source of this paper about the history of EIS.

\section{References}

[1] A. A. Mills, Bull. Scientif. Instrum. Soc., 68 (2001) 34.

[2] A. Frood,

http://newsvote.bbc.co.uk/mpapps/pagetools/print/news.bbc.co.uk/2/hi/science/nature/2804257.stm

[3] G. Dupbpernell, Proc. of the Symp. on Selected Topics in the History of Electrochemistry, G. Dubpernell and J. H. Westbrook, Eds., The

Electrochemical Soc., Proc. Vol. 78-6 (1978) 1.

[4] G. Eggert, Gold Bull., 28 (1995) 12.

[5] C. Vlachou-Mogire, B. Stern, J. G. McDonnel, Nuclear Instr. and Meth. in Phys. Res., B 265 (2007) 558.

[6] E. Gigal, https://gigalinsights.com/2018/06/09/an-electroplating-experiment-i-did-thanks-topharaoh-pepi-i/

[7] Wikipedia, https://en.wikipedia.org/wiki/Baghdad_Battery

[8] G. M.Ingo, G. Guida, E. Angelini, G. di Carlo, A. Mezzi, and G. Padeletti, Accounts of Chem. Res., 46 (2013) 2365.

[9] W. A. Oddy, Endeavour, 15 (1991) 29.

[10] O. Vittori, Gold Bull., 12 (1979) 35.

[11] F. Kohlrausch and W. A Nippoldt, Ann. Der Phys., 138 (1869) 280.

[12] W. Weber, "Elektrodynamische Maassbestimmungen.Ueber ein allgemeines Grundgesetz der elektrischen Wirkung", Werke, Vol. III Galvanismus und Elektrodynamik, part 1, ed. H. Weber, Berlin: Julius Springer Verlag (1893) pp.25-214. Reedition from Prince Jablonowski Society, Leipzig (1846) pp. 211-378.

[13] F. Kohlrausch, Ann. der Phys., 143 (1874) 290.

[14] F. Kohlrausch, Ann. der Phys., 148 (1873) 143.

[15] H. Herwig, Wiedemann Ann., 2 (1877) 566.

[16] R. Colley, Wiedemann Ann., 6 (1879) 206.

[17] M. Wien, Ann der Phys., 58 (1896) 37.

[18] E. Neumann, Ann. der Phys., 67 (1899) 499.

[19] E. Warburg, Ann. der Phys., 6 (1901) 125.

[20] C. F. Varley, Phil.Trans., 161 (1871) 129.

[21] H. F. Haworth, Trans. Farad. Soc., 16 (1920) 365

[22] R. T. Latey, Phil. Mag., 50 (1925) 444. 
[23] B. B. Banerji, Trans. Farad. Soc., 22 (1926) 9.

[24] N. Thon, Comptes Rendus Acad. Sciences Paris, 198 (1934) 1681.

[25] C. C. Murdock and E. E. Zimmerman, J. Applied Phys., 7 (1936) 211.

[26] A. Hickling, Trans. Farad. Soc., 38 (1942) 27.

[27] V. G. Levich, Acta Physicochim. U.S.S.R., 17 (1942) 257.

[28] V. G. Levich, Physicochemical Hydrodynamics, Prentice Hall, Englewoods Cliffs (1962).

[29] J. E. B. Randles, Disc. Faraday Soc., 1 (1947) 11.

[30] H. Gerischer and W. Mehl, Z. fur Elektrochem., 59 (1955) 1049.

[31] J. Llopis, J. Fernandez-Biarge, M. Perez-Fernandez, Electrochim. Acta, 1 (1959) 130.

[32] D. C. Grahame, J. Electrochem. Soc., 99 (1952) 370C.

[33] J. O’M. Bockris, B. E. Conway, J. Chem. Phys., 28 (1958) 707.

[34] H. A. Laitinen, R. A. Osteryoung, J. Electrochem. Soc.,102 (1955) 598.

[35] J. H. Sluyters and J. J. C. Oomen, Recueil des travaux chimiques des PaysBas, 79 (1960) 1101.

[36] I. Epelboin and G. Loric, J. Phys. Radium, 21 (1960) 74.

[37] R. de Levie, Electrochim. Acta, 8 (1963) 751.

[38] R. de Levie, Electrochim. Acta, 9 (1964) 1231.

[39] S. K. Rangarajan, J. Electroanal. Chem., 22 (1969) 89.

[40] P. Drossbach and J. Schulz, Electrochim. Acta, 9 (1964) 1391.

[41] J. Llopis and F. Colom, Anal. Real Soc. Espanol. Fis. Quim., 52A (1956) 233.

[42] M. Orazem and B. Tribollet, Electrochemical Impedance Spectroscopy, John Wiley \& Sons, Hoboken, 2008.

[43] J. Newman, J. Electrochem.Soc., 117 (1970)

[44] M. L. Boyer, I. Epelboin, M. Keddam, Electrochim. Acta, 11 (1966) 221.

[45] M. Keddam, $\mathrm{PhD}$ thesis (1967).

[46] I. Epelboin and M. Keddam, J. Electrochem. Soc., 117 (1970) 1052.

[47] I. Epelboin, M. Keddam, J. C. Lestrade, Disc. Faraday Soc., 56 (1973) 264.

[48] C. Deslouis, I. Epelboin, M. Keddam, J. C. Lestrade, J. Electroanal. Chem., 28 (1970) 57.

[49] E. R. Brown, D. E. Smith, G. L. Booman, Anal. Chem., 40 (1968) 1411.

[50] C. Gabrielli, Identification of electrochemical processes by frequency

response analysis, Technical report $n^{\circ}$ 004/83, Solartron, Farnborough (1983).

[51] C. Gabrielli, PhD thesis (1973).

[52] I. Epelboin, C. Gabrielli, M. Keddam, et al., J. Electrochem. Soc., 119

(1972) 1632.

[53] C. Gabrielli and M. Keddam, J. Electroanal. Chem., 45 (1973) 267.

[54] I. Epelboin, C. Gabrielli, M. Keddam, H. Takenouti, Z. Physik. Chem. NF, 98 (1975) 215.

[55] H. Schweickert, W. J. Lorenz, H. Friedburg, J. Electrochem. Soc., 127 (1980) 1693. 
[56] L. M. Baugh, N. C. White, J. Applied Electrochem., 17 (1987) 1037.

[57] C. Ho, I. D. Raistrick, R. A Huggins, J. Electrochem. Soc., 127 (1980) 343.

[58] O. E. Barcia, J. L. Camara, O. R. Mattos, J. Applied Electrochem., 17 (1987) 641.

[59] S. P S. Badwal, F. T. Ciacchi, Solid State Ionics, 18 (1986) 1054.

[60] S. Yamanaka et al, Mat. Sci. Eng., B2 (1989) L5.

[61] S. C. Creason, J. W. Hayes, D. E. Smith, J. Electroanal. Chem., 47 (1973) 9.

[62] G. S. Popkirov, R. N. Schindler, Rev. Sci. Instr., 64 (1993) 3111.

[63] Z. Stoynov, B. Savova-Stoynov, T. Kossev, J. Power Sources, 30 (1990) 275.

[64] D. D. Macdonald and M. Urquidi-Macdonald, J. Electrochem. Soc., 132 (1985) 2316.

[65] M. Urquidi-Macdonald, S. Real, D. D. Macdonald, J. Electrochem. Soc., 133 (1986) 2019.

[66] C. Gabrielli and B. Tribollet, J. Electrochem. Soc., 141, (1994) 1147.

[67] C. Gabrielli, M. Keddam, N. Nadi, H. Perrot, Electrochim. Acta, 44, (1999) 2095.

[68] C. Gabrielli, M. Keddam, H. Perrot et al, Electrochim. Acta, 44, (1999) 4217.

[69] B. Tribollet and J. Newman, J. Electrochem. Soc., 130, (1983) 2016.

[70] C. Deslouis and B. Tribollet, Electrochim. Acta, 35, (1990) 1637.

[71] R. S. Lillard, P. J. Moran, H. S. Isaacs, J. Electrochem. Soc., 139, (1992) 1007.

[72] E. Bayet, F. Huet, M. Keddam, K. Ogle, H. Takenouti, J. Electrochim. Soc., 144, (1997) L87.

[73] M. E. Orazem, B. Tribollet, V. Vivier et al, J. Electrochem. Soc., 154, (2007) C719.

[74] S. L. Wu, M. E. Orazem, B. Tribollet, V. Vivier, J. Electrochem. Soc., 156, (2009) C28. 


\section{FIGURES CAPTIONS}

Figure 1: Scheme of a Wheastone bridge. $G$ generator, $D$ detector.

Figure 2: Bifilar dynamometer used as a detector in the Kohlrausch bridge. (reprinted from W. Weber, "Elektrodynamische Maassbestimmungen.Ueber ein allgemeines Grundgesetz der elektrischen Wirkung”, Werke, Vol. III Galvanismus und Elektrodynamik, part 1, ed. H. Weber, Berlin: Julius Springer Verlag (1893) pp.25-214. Reedition from Prince Jablonowski Society, Leipzig (1846) pp 211-378).

Figure 3: The generator of the Kohlrausch bridge. $m$ is the magnetic plate on the rotating disc, and $M$ is the multiplier (reprinted from F. Kohlrausch, "Ueber die wirkung der polarisation auf alternirende strome und uber einen sinus-induktor", Ann. der Phys., (1874), 143 pp 290-308. Copyright Wiley-VCH Verlag GmbH \& Co. KGaA. Reproduced with permission)

Figure 4: Insertion of a 2-electrode cell $C$ in a Kohlrausch bridge.

Figure 5: Change of the resistance between the 2 electrodes of an electrolytic cell with respect to the distance between the 2 gold electrodes in $0.002 \mathrm{~N} \mathrm{KBr}$ electrolyte at $3400 \mathrm{~Hz}$. (reprinted with permission from C. W. Miller, Phys. Rev., 22, p 622 (1923). Copyright 1923 by the American Physical Society).

Figure 6: Change of the polarisation capacity with respect to the amplitude of the current at $130 \mathrm{~Hz}$. (reprinted from E. Neumann, "Ueber die polarisationcapacitat unkehrbarer elektroden" Ann. der Phys., (1899) 67, pp 500-534. Copyright Wiley-VCH Verlag GmbH \& Co. KGaA. Reproduced with permission)

Figure 7: Change of the polarisation capacity with respect to $1 / \sqrt{f}$. The right part of the curve, which characterizes the low frequency, is proportional to $1 / \sqrt{f}$ showing that Warburg theory is valid in this frequency range. (Republished with permission of Royal Society of Chemistry, from "The electrode capacity and resistance of electrolytes for a wide range of frequencies" by B B Banerji, Trans. Faraday Soc., 22, p 111 (1926); permission conveyed through Copyright Clearance Center, Inc..).

Figure 8: Measurement of the polarization impedance from $0.05 \mathrm{~Hz}$ to $4 \mathrm{kHz}$ for a platinum electrode immersed in $0.25 \mathrm{~N} \mathrm{H}_{2} \mathrm{SO}_{4}$ (Republished with permission of American Institute of Physics, from "Polarization impedance at low frequencies" by C. C. Murdock and Zimmerman, J. Applied Phys., 7, p 211 (1936); permission conveyed through Copyright Clearance Center, Inc..). 
-a- Measurement equipment used for frequencies below $20 \mathrm{~Hz}$.

-b- Log-log plot of the real and imaginary parts of the polarization impedance.

Figure 9: Scheme of the potentiostat devised by Hickling. (Republished with permission of Royal Society of Chemistry, from "Studies in electrode polarisation, part IV - The automatic control of the potential of a working electrode" by A. Hickling, Trans. Faraday Soc., 38, p 27 (1942); permission conveyed through Copyright Clearance Center, Inc..).

Figure 10: The rotating disc electrode.

-a- Cross section of a rotating disc electrode.

-b- Example of current-voltage curves obtained on a platinum electrode in $10^{-3} \mathrm{M} \mathrm{Fe}(\mathrm{CN})_{6}^{3-}$ for rotation speeds of the electrode ranging from 1600 and 10000 rpm. (Reprinted from J. Electroanal. Chem., Vol. 28, by C. Deslouis, I. Epelboin, M. Keddam, J. C. Lestrade, "Impedance de diffusion d'un disque tournant en régime hydrodynamique laminaire. Etude expérimentale et comparaison avec le modèle de Nernst." p 57 (1970) with permission from Elsevier).

Figure 11: Randles equivalent circuit where $R_{e}$ is the electrolyte resistance and $C_{d l}$ is the double layer capacity.

-a- The original equivalent circuit with frequency dependent $C_{r}$ and $R_{r}$

(Republished with permission of Royal Society of Chemistry, from "Kinetics of rapid electrode reactions" by J. E. B. Randles, Disc. Faraday Soc., 1, p11 (1947); permission conveyed through Copyright Clearance Center, Inc..).

-b- Evolution of the Randles equivalent circuit with frequency independent transfer function $R_{t}$ and the Warburg impedance $W(\omega)$.

Figure 12: Reaction mechanism including electron transfer, adsorption and diffusion employed by Llopis et al. (Reprinted from Electrochim. Acta, Vol. 1, by J. Llopis, J. Fernandez-Biarge, M. Perez Fernandez, "Study of the impedance of a platinum electrode in a redox system.", p 130 (1959) with permission from Elsevier.).

Figure 13: Plot of the electrochemical impedance $Z=Z^{\prime}-i Z^{\prime \prime}$ in the complex plane (Reprinted from J. H. Sluyters and J. J. C. Oomen: "On the impedance of galvanic cells. II Experimental verification », Recueil des travaux chimiques des Pays-Bas, (1960) 79, p 1101. Copyright Wiley-VCH Verlag GmbH \& Co. KGaA. Reproduced with permission.). 
-a- Impedance of an electron transfer limited by diffusion obtained on platinum in $2.10^{-6} \mathrm{M} \mathrm{Hg}_{2}^{2+}$ in $1 \mathrm{NHClO}_{4}$ (frequencies in $\mathrm{Hz}$ ).

-b- Impedance of a slow reaction obtained on platinum immersed in $8.10^{-6} \mathrm{MZn}^{2+}$ in $1 \mathrm{M} \mathrm{NaClO}_{4}+10^{-3} \mathrm{~N} \mathrm{ClO}_{4}$ (frequencies in $\mathrm{kHz}$ ).

Figure 14: Plot of the electrochemical impedance $Z=R-j G$ in the complex plane obtained for the oxidation of aluminium in $\mathrm{H}_{3} \mathrm{PO}_{4}$ at $0.25 \mathrm{~V}$ and $19.5 \mathrm{~V}$ (electrochemical polishing) between $20 \mathrm{~Hz}$ to $2 \mathrm{kHz}$ (frequencies in $\mathrm{Hz}$ ). (Reprinted from I. Epelboin, G. Loric, "Sur un phénomène de résonance observé en basse fréquence au cours des électrolyses accompagnées d'une forte surtension anodique », J. Phys. Radium, (1960) 21, p 74. Reproduced with permission.).

Figure 15: The equivalent circuit of a pore. (Reprinted from Electrochimica Acta, Vol. 9, by R. De Levie, "On porous electrodes in electrolyte solutions IV”, p 1231 (1964) with permission from Elsevier.).

Figure 16: Plot of the theoretical electrochemical impedance $Z=R+j G$ in the complex plane calculated for an electron transfer limited by the diffusion in a layer of finite thickness. (Reprinted from Electrochim. Acta, Vol. 9, by P. Drossbach and J. Schulz, "Elektrochemische untersuchungen an kohleelektroden - I Die uberspannung des wasserstoffs", p 1391 (1964) with permission from Elsevier.).

Figure 17: -a- Scheme of a wideband potentiostat for polarizing a 3-electrode cell (Reprinted from Electrochim. Acta, Vol. 11, by M. L. Boyer, I. Epelboin, M. Keddam, from "Une nouvelle méthode potentiocinétique d'étude des processus électrochimiques rapides.”, p 221 (1966) with permission from Elsevier.).

-b- Plot of the electrochemical impedance $Z=R-j G$ in the complex plane (frequency in $\mathrm{kHz}$ ) obtained for chromium in $\mathrm{H}_{2} \mathrm{SO}_{4}$ at $1.16 \mathrm{~V} / \mathrm{ECS}$.

Figure 18: Experimental and theoretical electrochemical impedances obtained for dissolution of iron in sulfuric acid medium. (Republished with permission of Royal Society of Chemistry, from "Faradaic impedances and intermediates in electrochemical reactions" by I. Epelboin, M. Keddam, J.-C. Lestrade, Faraday Discuss. Chem. Soc., 56, p 264 (1973); permission conveyed through Copyright Clearance Center, Inc..). 
-a- Impedances measured on an iron electrode in (up) $1 \mathrm{M} \mathrm{H}_{2} \mathrm{SO}_{4}, \mathrm{pH}=0.03$ at $0.39 \mathrm{~V} / \mathrm{ECS}$ and (down) $0.0012 \mathrm{M} \mathrm{H}_{2} \mathrm{SO}_{4}+1 \mathrm{M} \mathrm{Na}_{2} \mathrm{SO}_{4}, \mathrm{pH}=3.5$ at -0.48 $\mathrm{V} / \mathrm{ECS}$.

-b- Equivalent circuit and scheme of the theoretical impedance (a) inductive and (b) capacitive at various potentials.

Figure 19: Plot of the electrochemical impedance $Z=R-j G$ in the complex plane obtained for platinum in $10^{-3} \mathrm{M} \mathrm{Fe}(\mathrm{CN})_{6}^{3-}$ measured between 0.15 and $180 \mathrm{~Hz}$ on a disc electrode rotating at $1800 \mathrm{rpm}$ for currents equal to (x) $i=$ $i_{d} / 4,(\bullet \bullet \bullet) i=i_{d} / 2,(\bigcirc \circ \bigcirc) i=3 i_{d} / 4$ where $i_{d}$ is the diffusion limiting current. (Reprinted from J. Electroanal. Chem., Vol. 28, by C. Deslouis, I. Epelboin, M. Keddam, J. C. Lestrade, "Impedance de diffusion d'un disque tournant en régime hydrodynamique laminaire. Etude expérimentale et comparaison avec le modèle de Nernst." p 57 (1970) with permission from Elsevier).

Figure 20: Operational amplifiers.

-a- Electrical equivalent circuit of an ideal operational amplifier.

-b- Simple feedback loop on an operational amplifier: wideband potentiostat which imposes $V_{R}=E$ where $V_{R}$ is the potential imposes to the working electrode with respect to a reference electrode and $E$ is the desired imposed potential on the electrode.

Figure 21: Scheme of a transfer function analyser. (Reprinted from C. Gabrielli, "Identification of electrochemical processes by frequency response analysis.", Technical report $n^{\circ}$ 004/83, Solartron, Farnborough (1983). Reproduced with permission).

-a- Scheme of the working principle of a transfer function analyser used to analyse a system with a transfer function $K(\omega) e^{j \varphi(\omega)}$.

-b- Example of a whole potentiostatic equipment.

Figure 22: Dissolution-passivation of a rotating disc iron electrode in sulfuric acid medium. (Republished with permission of The Electrochemical Society, from "Passivation of iron in sulfuric acid medium" by I. Epelboin, C. Gabrielli, M. Keddam, J.-C. Lestrade, H. Takenouti, J. Electrochem. Soc., 119, p 1632 (1972); permission conveyed through Copyright Clearance Center, Inc..). -a- Current-voltage curve. 
-b- Cross section of the iron electrode after polarization in the intermediate passivation branch.

-c- Current density-voltage curve. (Republished with permission of Royal Society of Chemistry, from "Faradaic impedances and intermediates in electrochemical reactions" by I. Epelboin, M. Keddam, J.-C. Lestrade, Faraday Discuss. Chem. Soc., 56, p 264 (1973); permission conveyed through Copyright Clearance Center, Inc..).

Figure 23: Electrochemical impedance measured for the dissolution-passivation of a rotating disc iron electrode in sulfuric acid medium. (Republished with permission of Royal Society of Chemistry, from "Faradaic impedances and intermediates in electrochemical reactions" by I. Epelboin, M. Keddam, J.-C. Lestrade, Faraday Discuss. Chem. Soc., 56, p 264 (1973); permission conveyed through Copyright Clearance Center, Inc..).

Figure 24: Calculated current-voltage curve for various rotation speeds of an iron electrode in sulfuric acid medium and the corresponding electrochemical impedance at various potentials. (Reprinted from I. Epelboin, C. Gabrielli, M. Keddam, H. Takenouti, from "A coupling between charge transfer and mass transport leading to multi-steady states. Application to localized corrosion.”, Z. Physik. Chem. NF, 98 (1975) pp 215-232 with permission from De Gruyter.). 


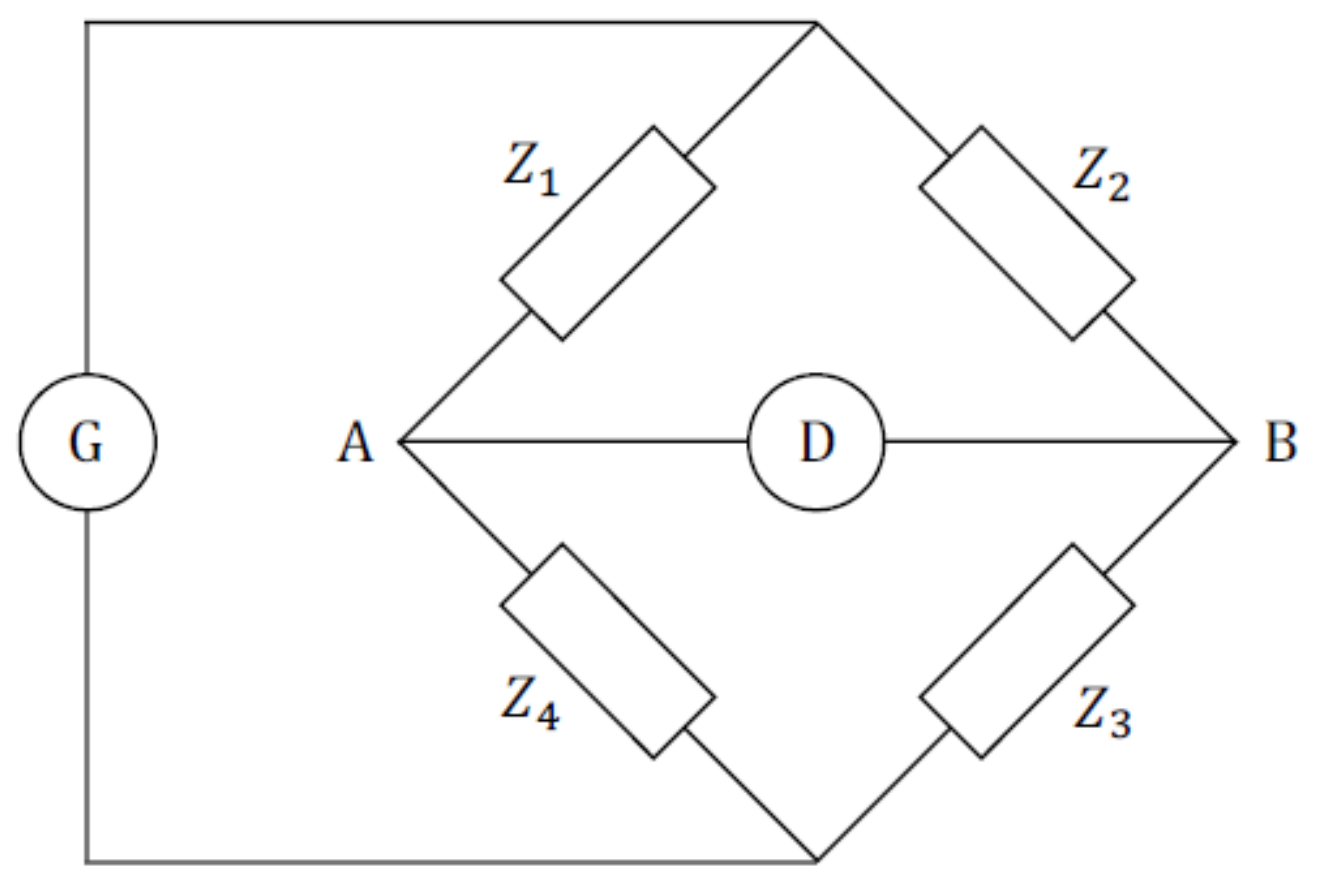

Figure 1 


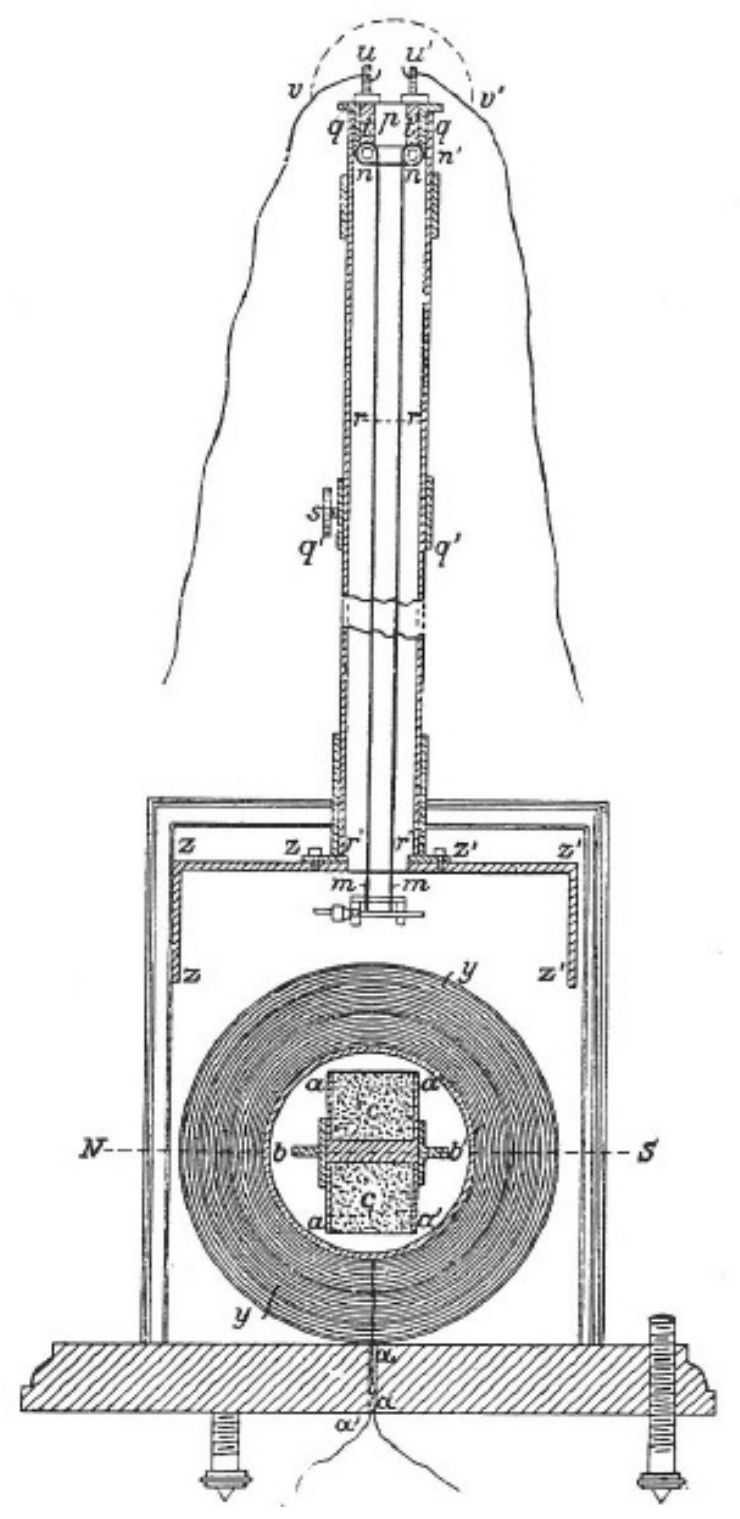

Figure 2 


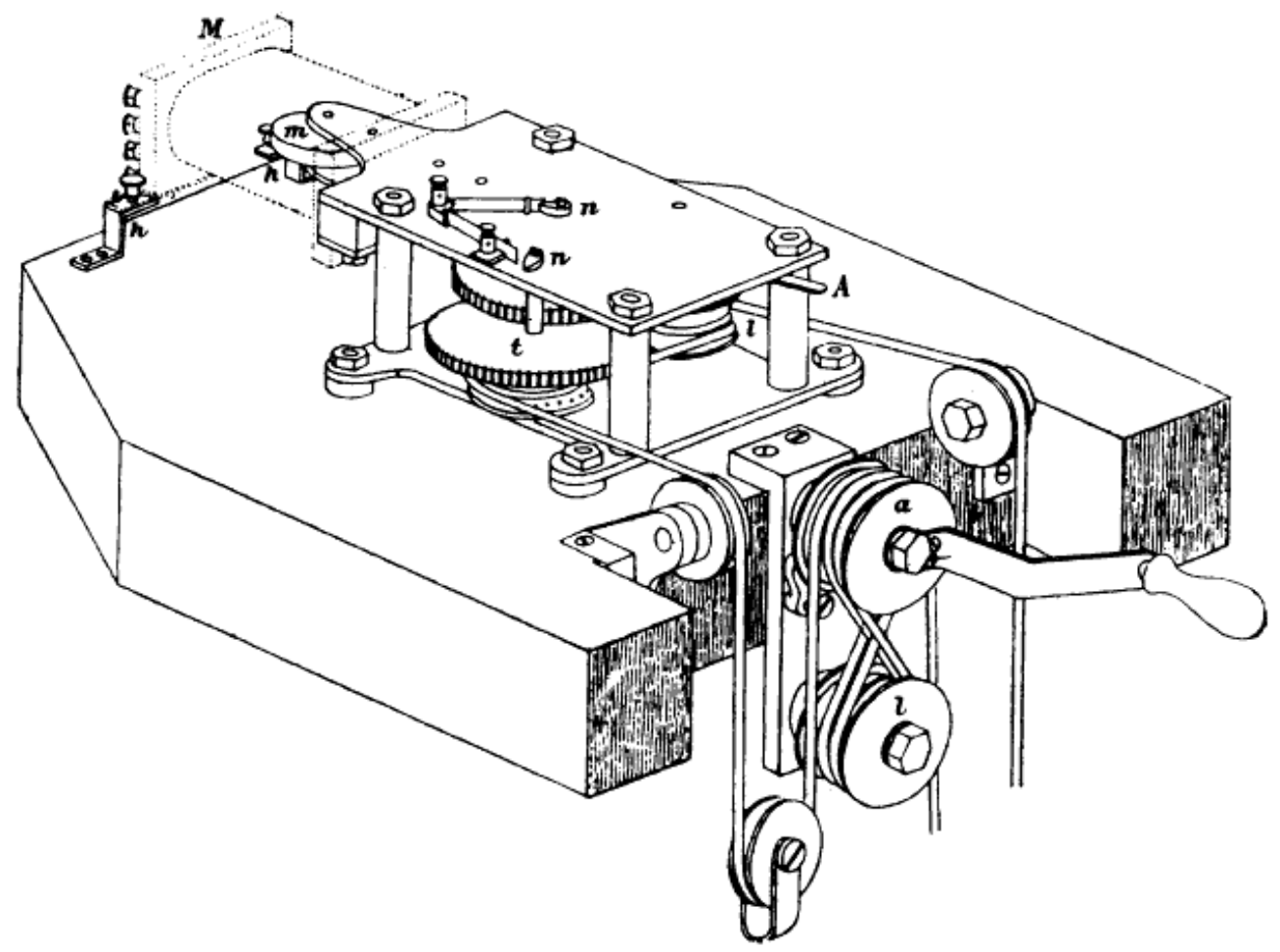

Figure 3 


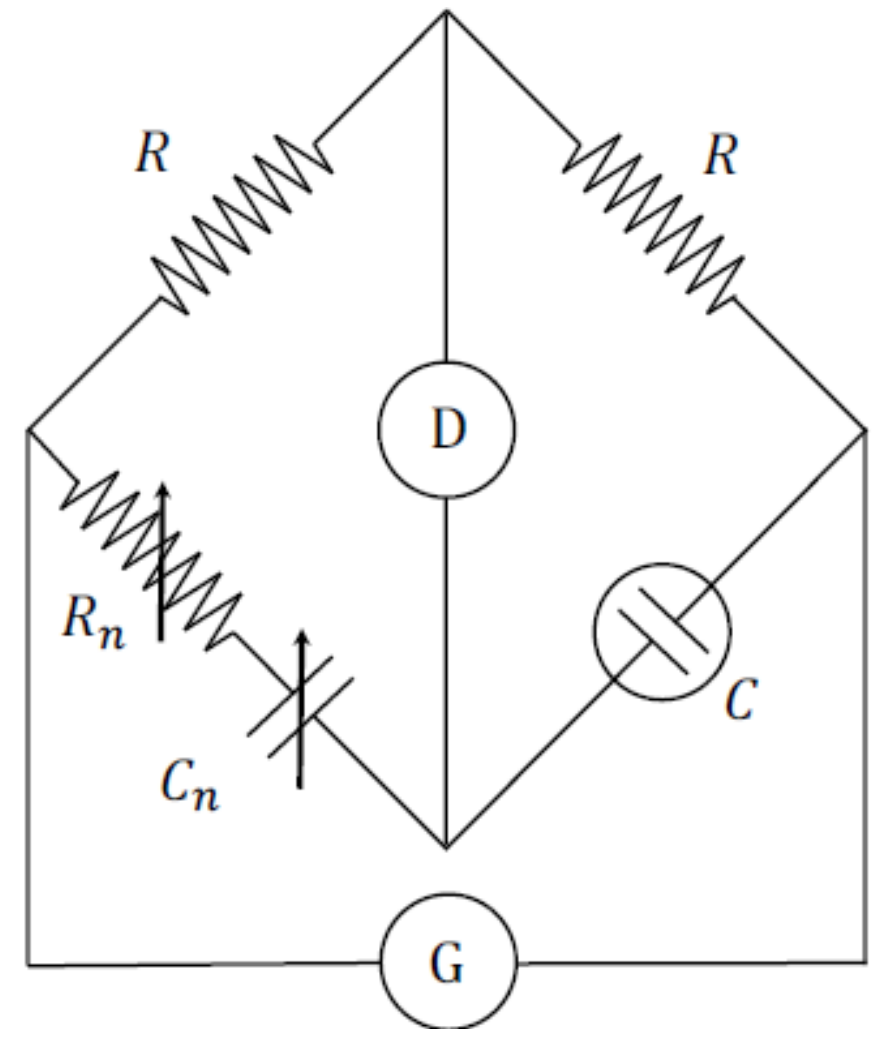

Figure 4 


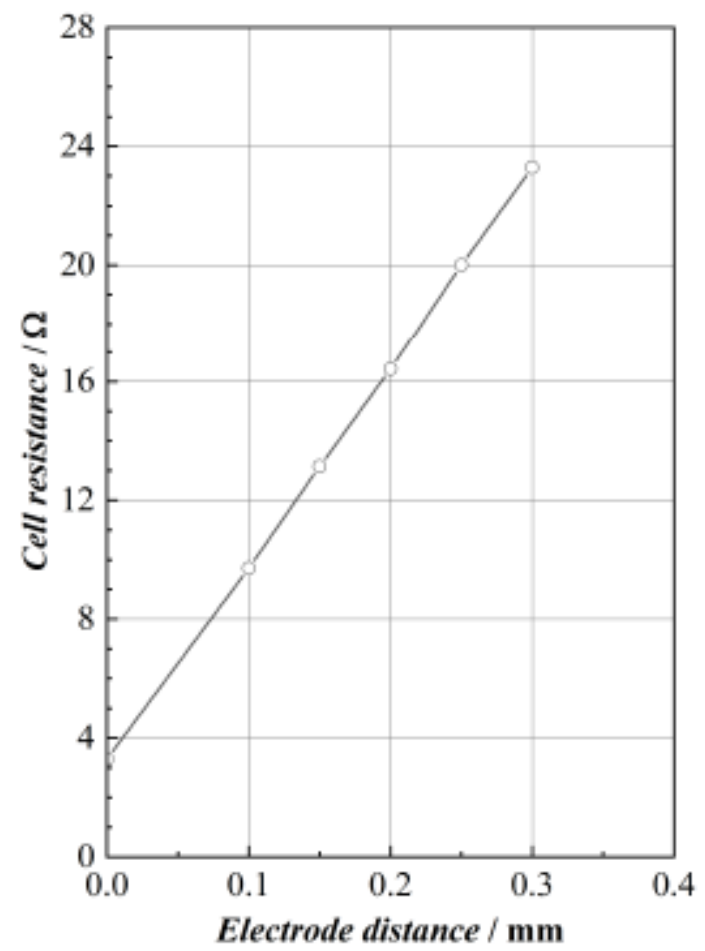

Figure 5 


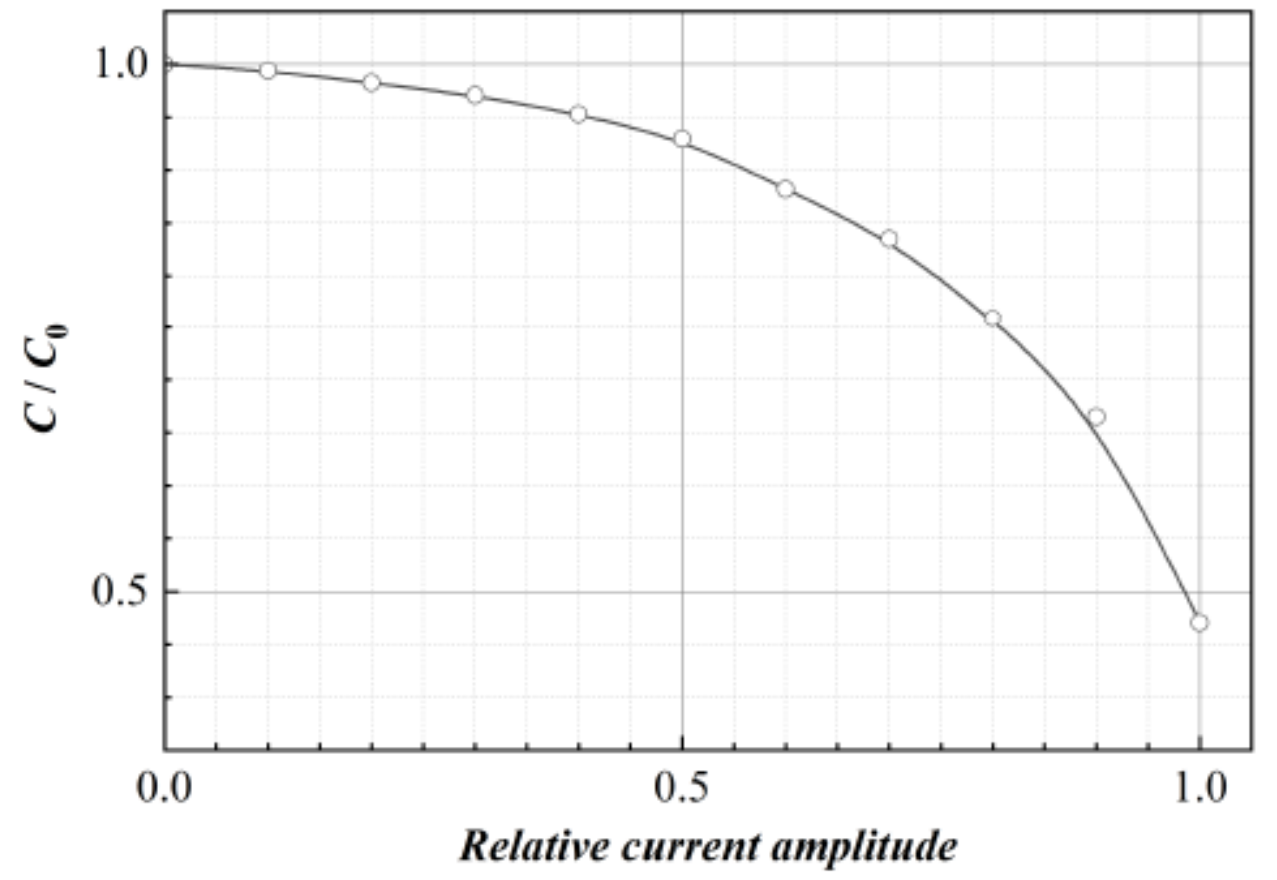

Figure 6 


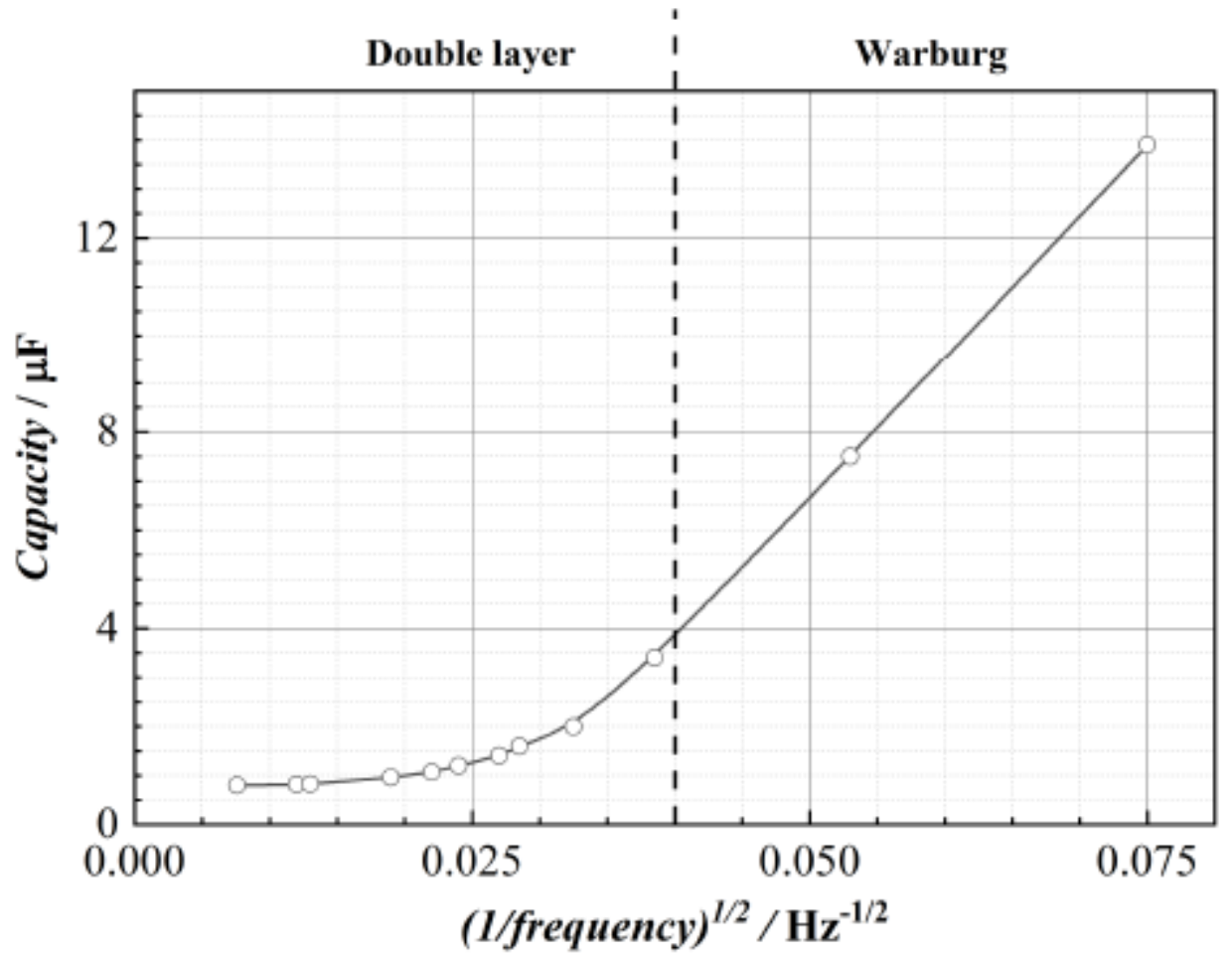

Figure 7 


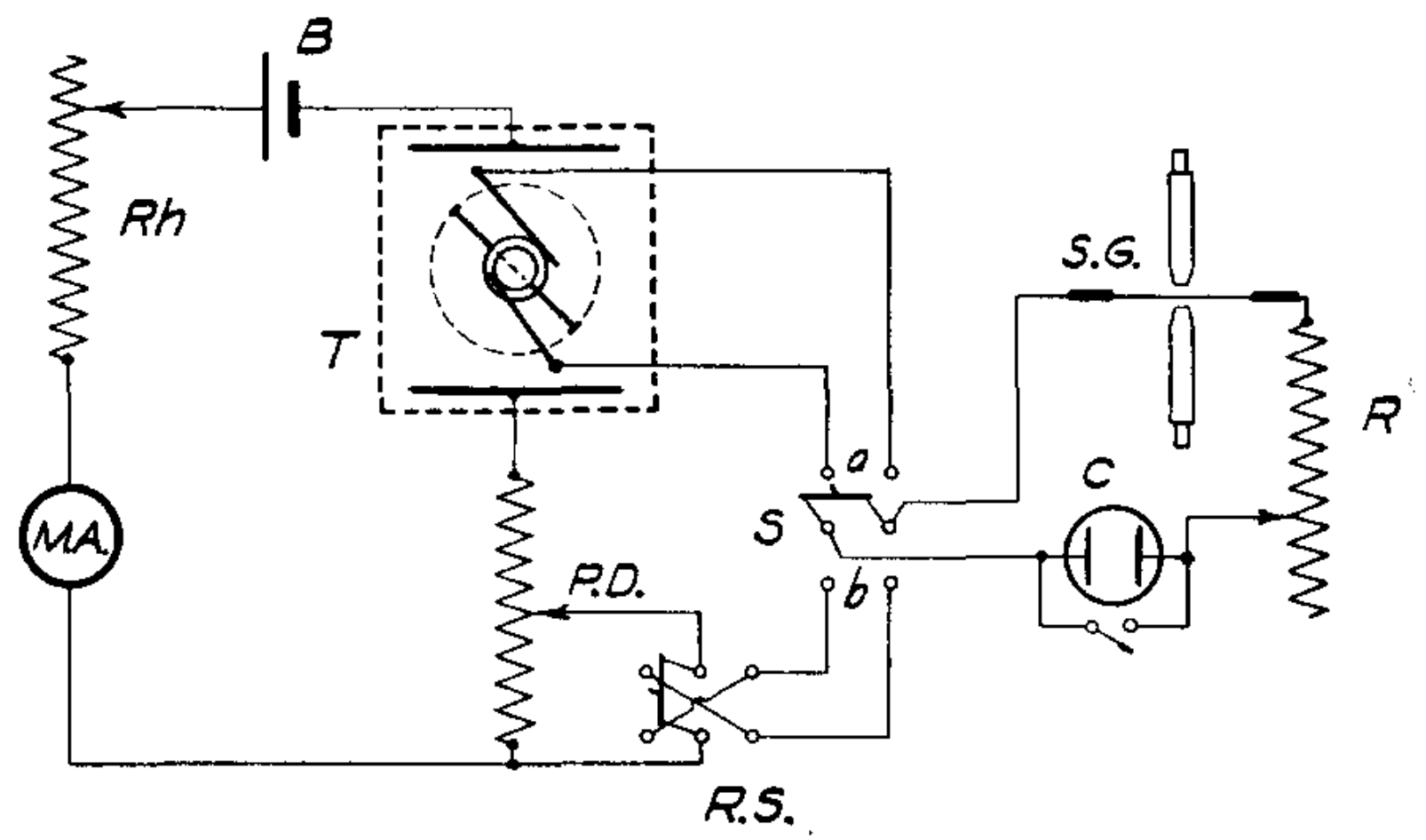

Figure 8a 


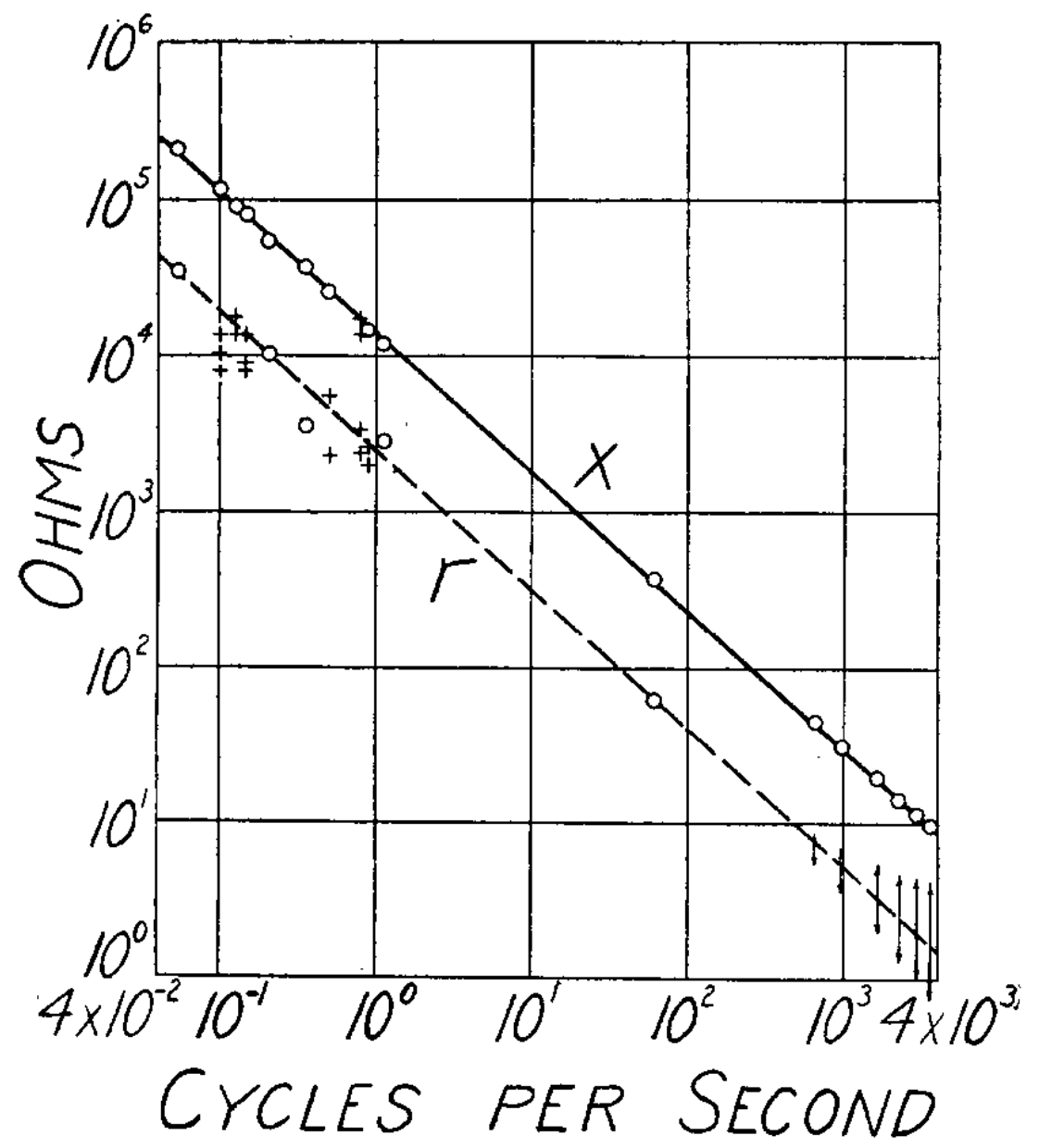

Figure $8 b$ 


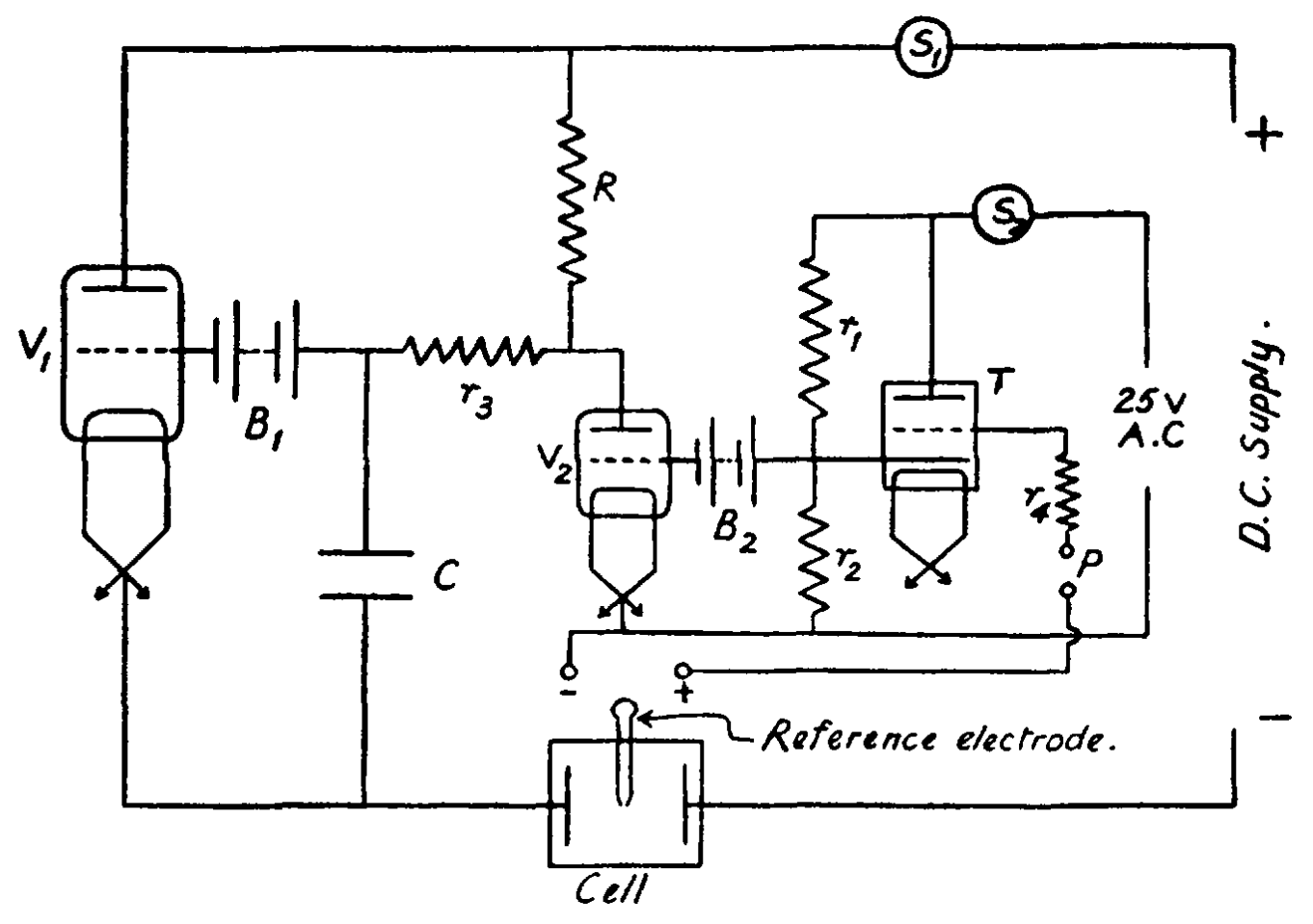

Figure 9 


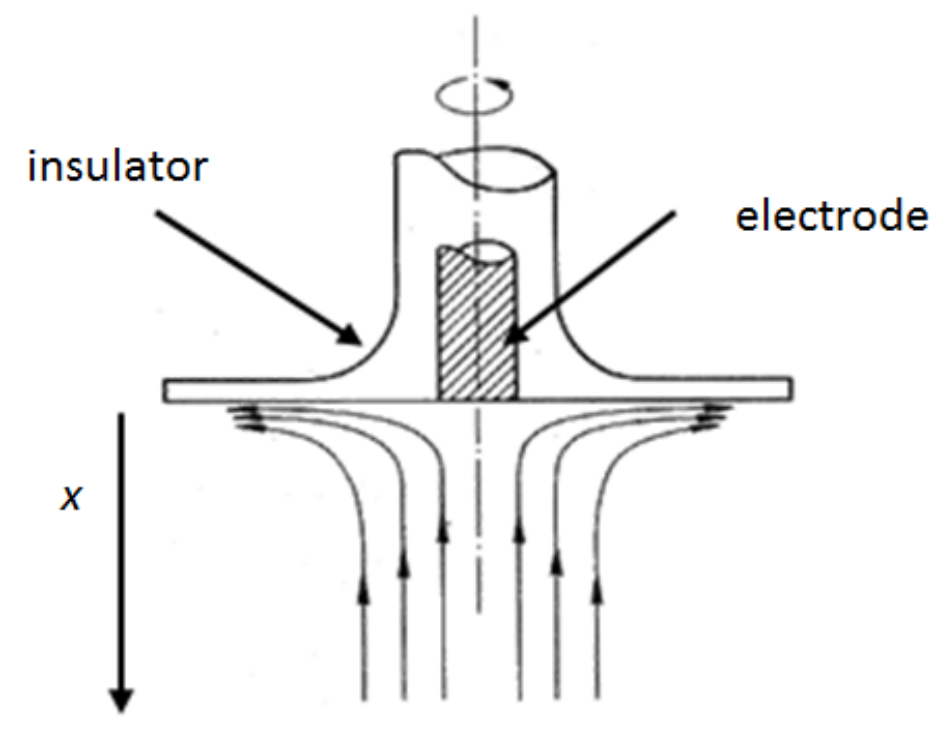

Figure 10a 


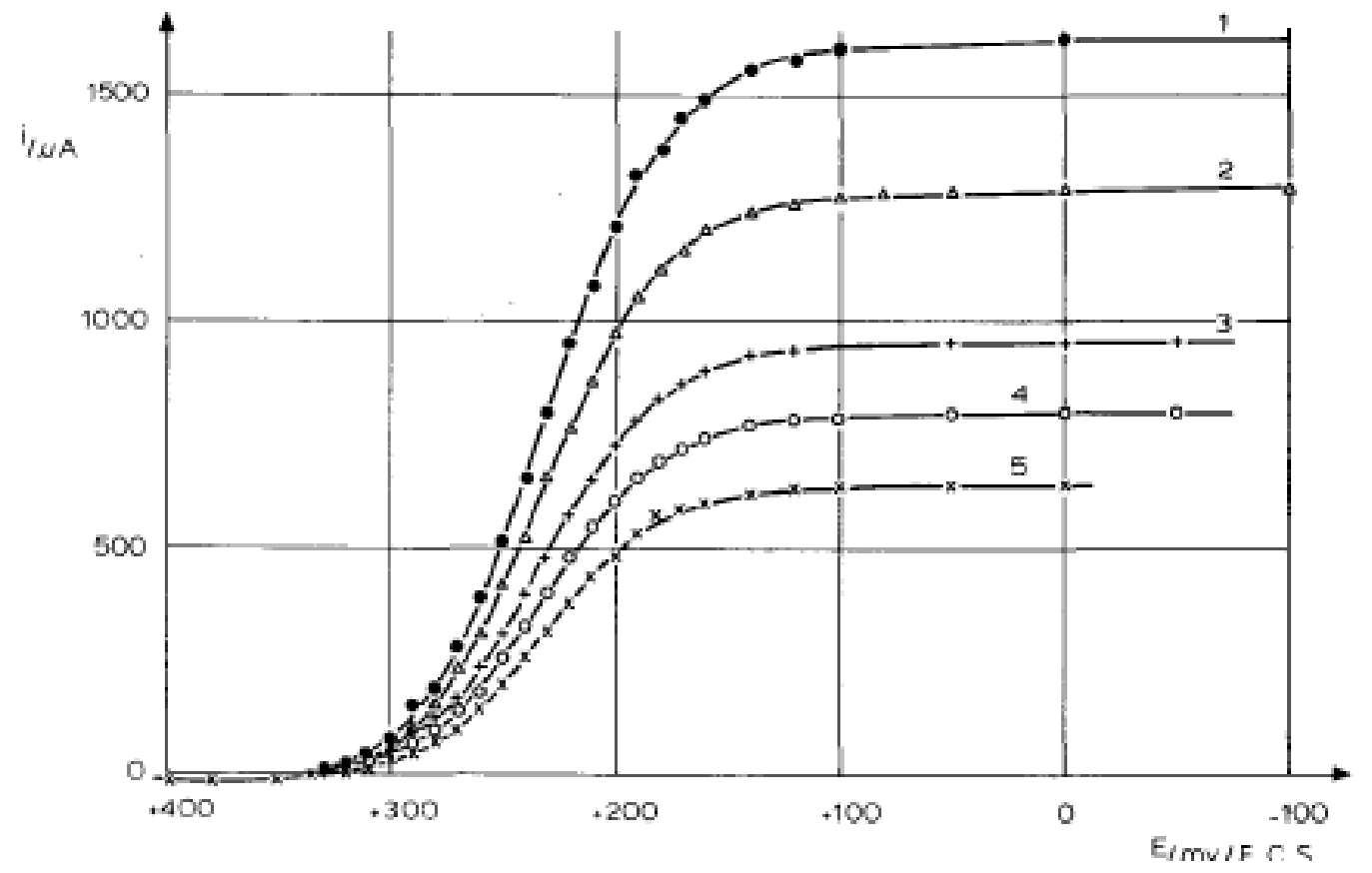

Figure $10 \mathrm{~b}$ 


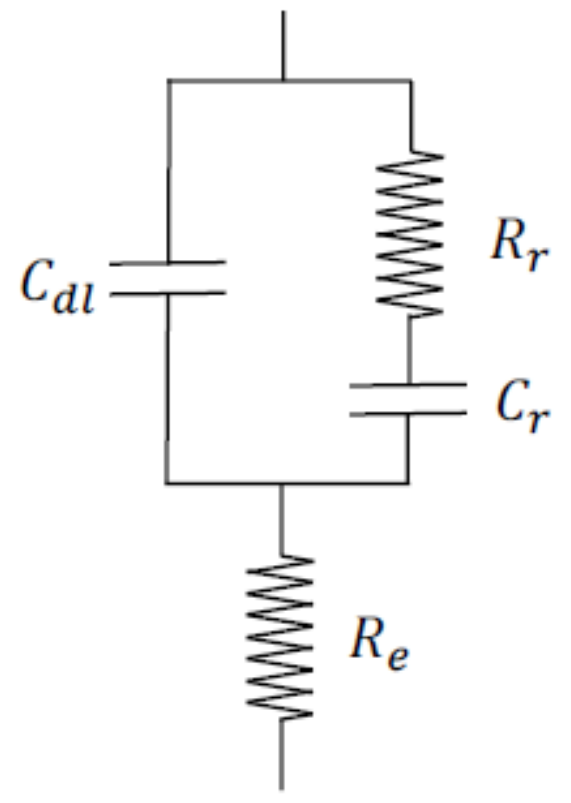

Figure 11a 


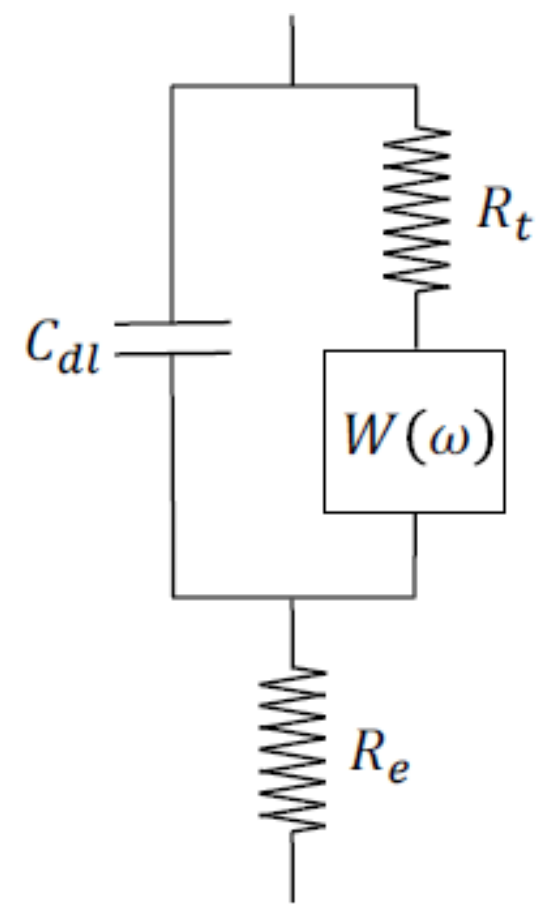

Figure 11b 


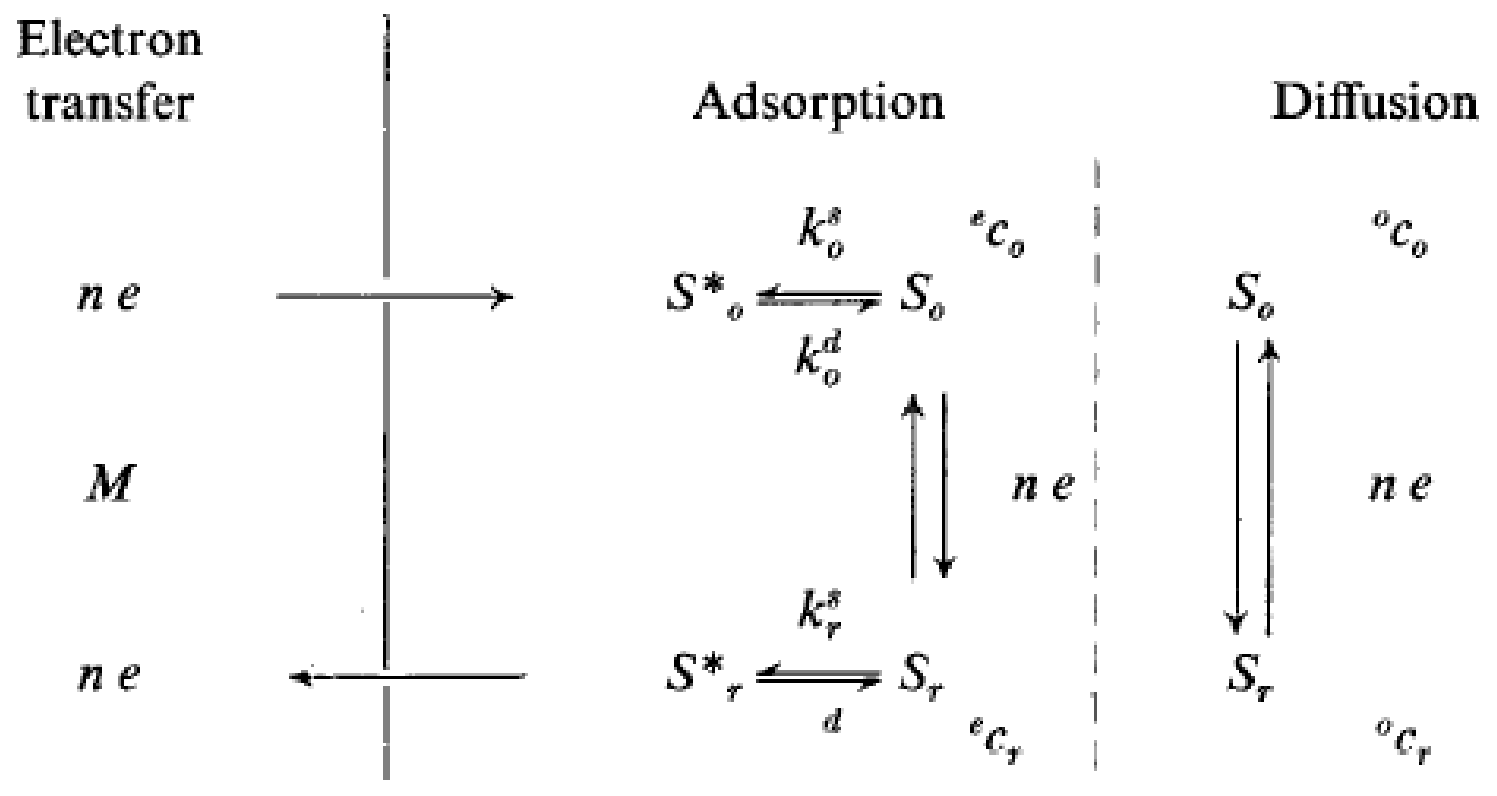

Figure 12 


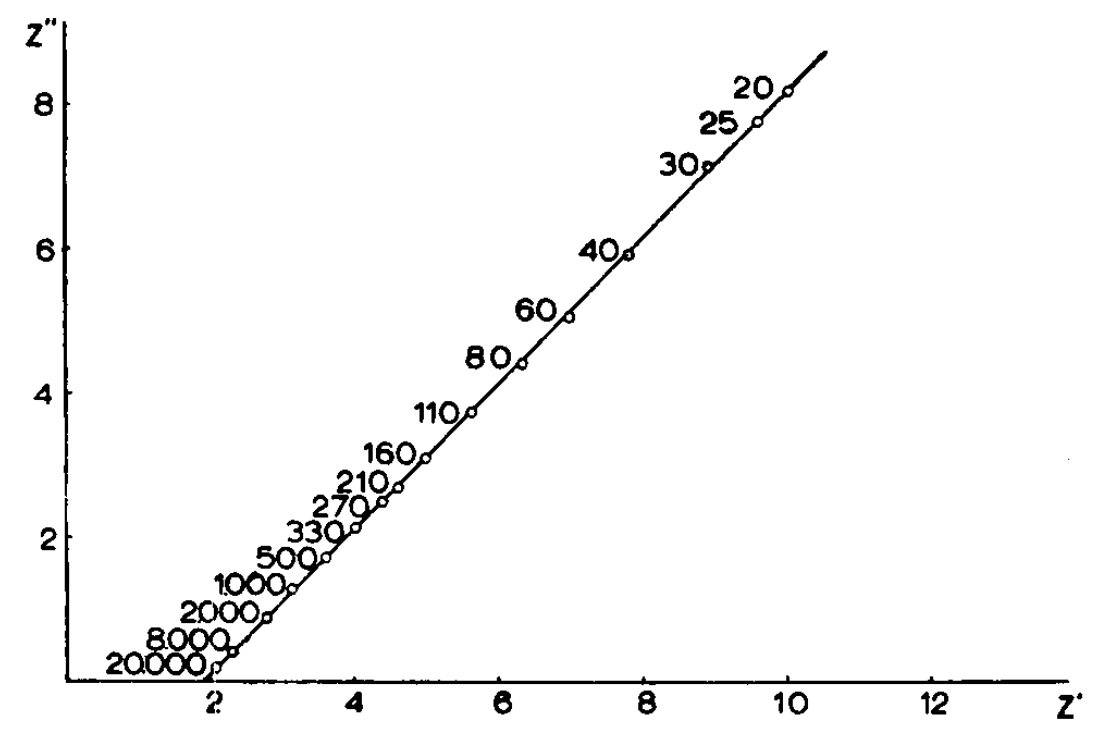

Figure 13a 


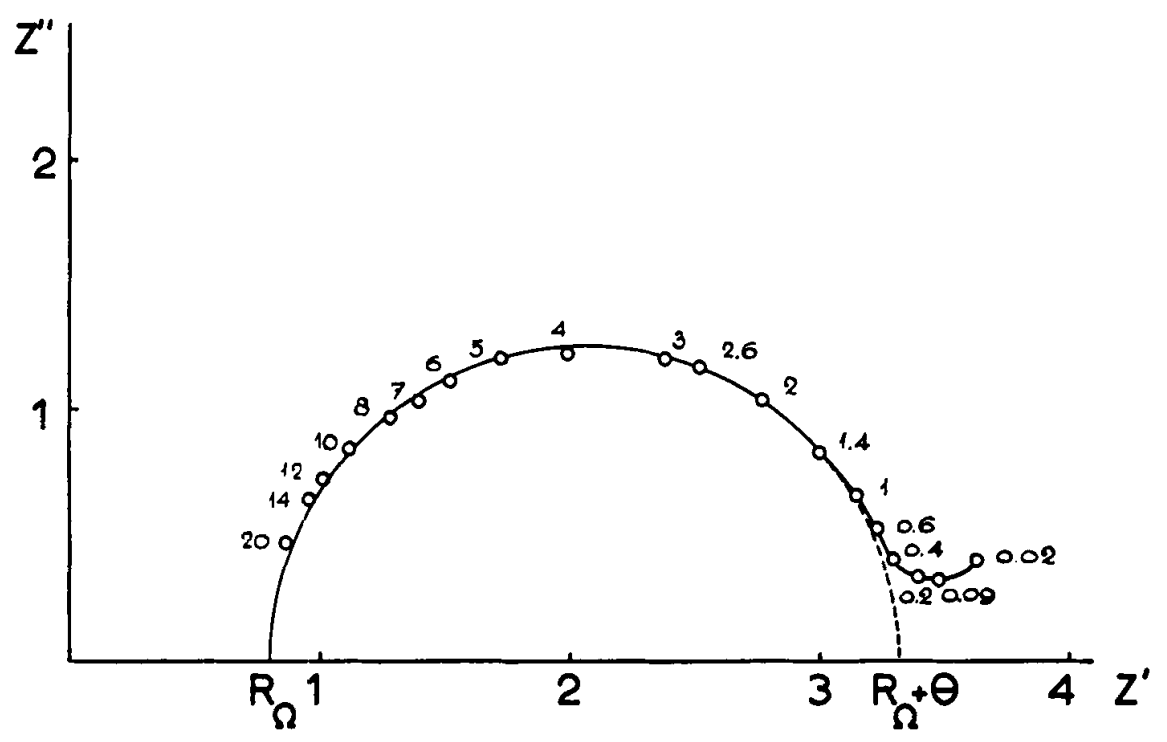

Figure 13b 


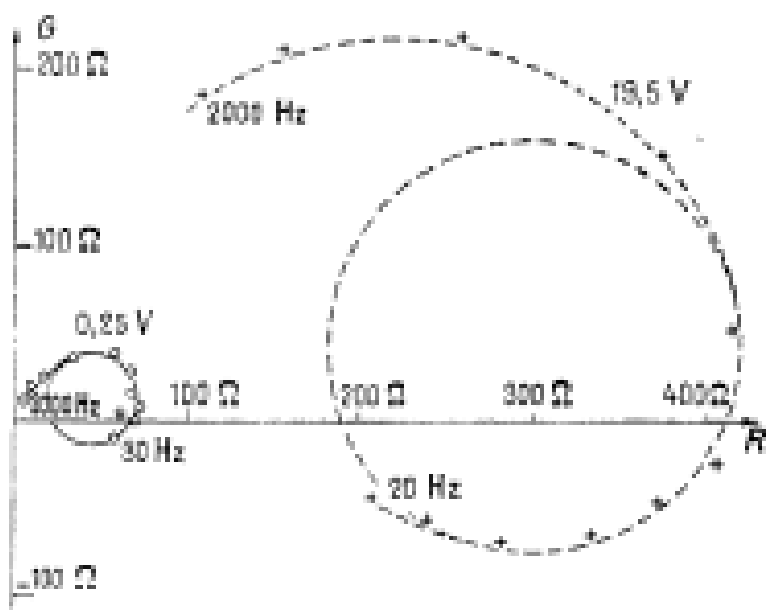

Figure 14 


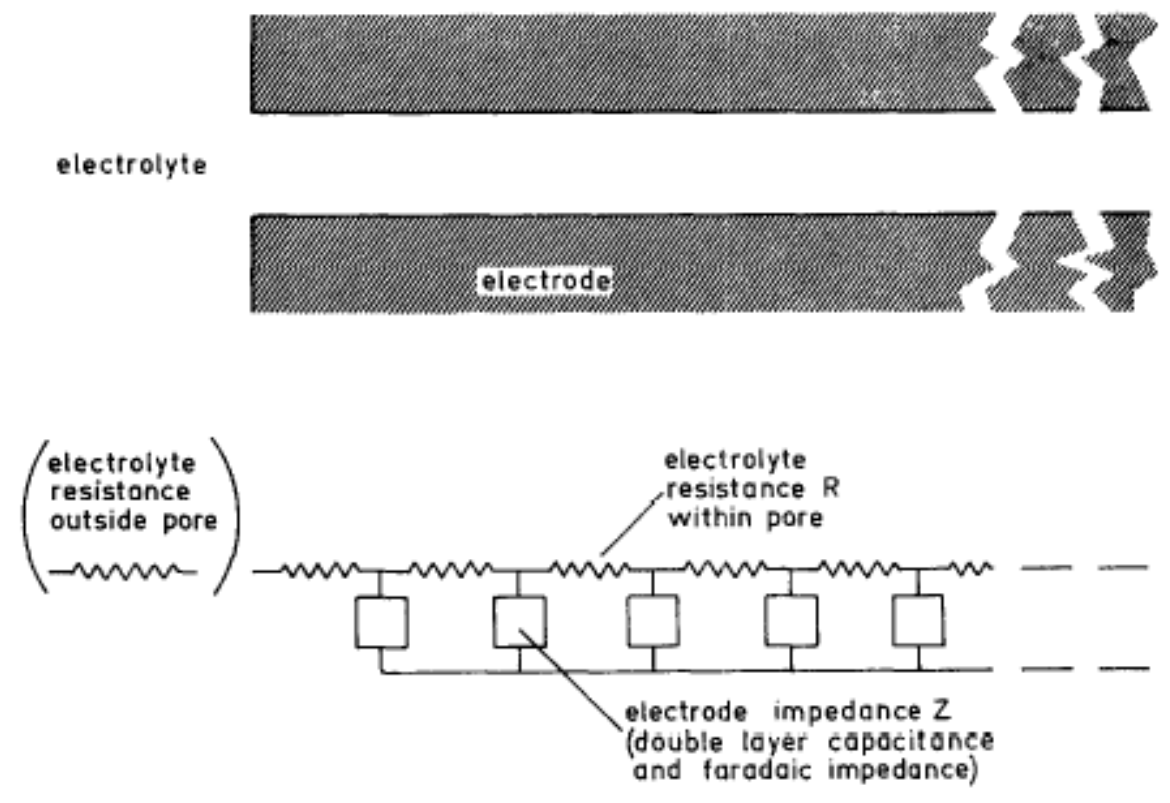

Figure 15 
reelle Achse

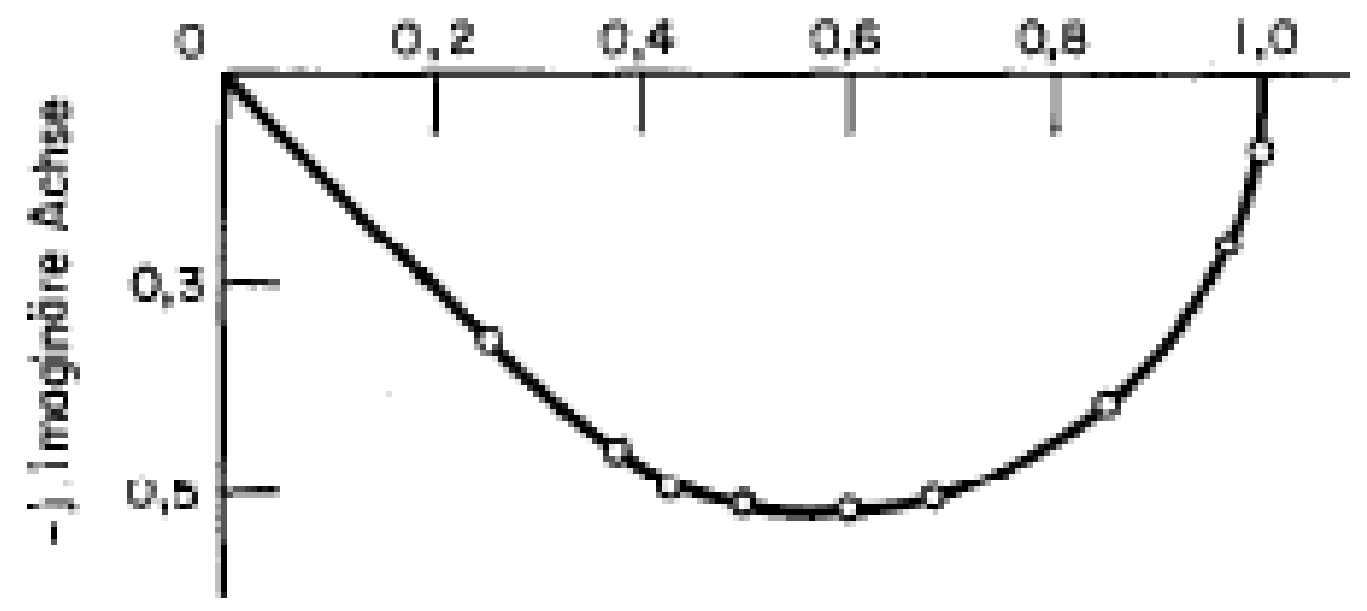

Figure 16 


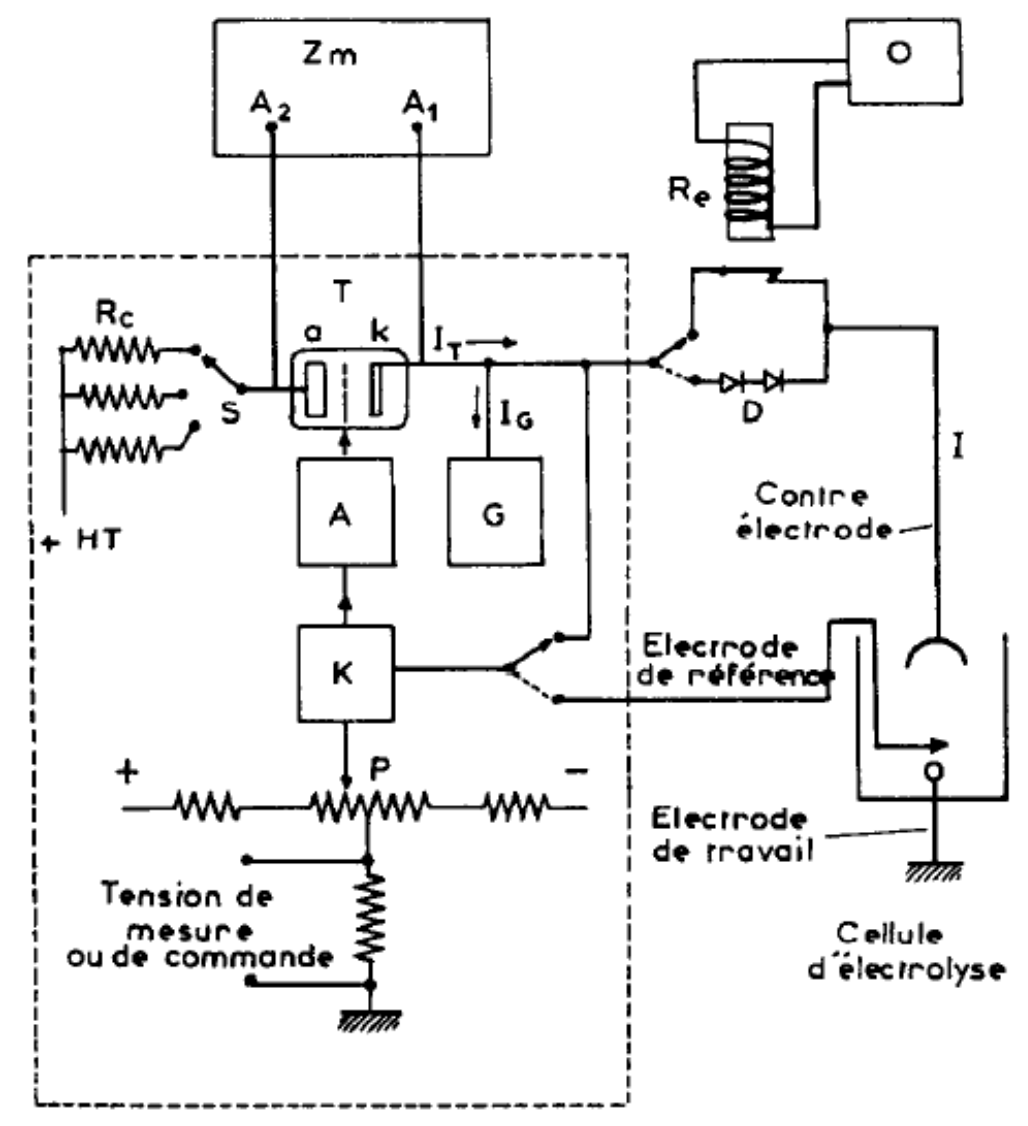

Figure 17a 


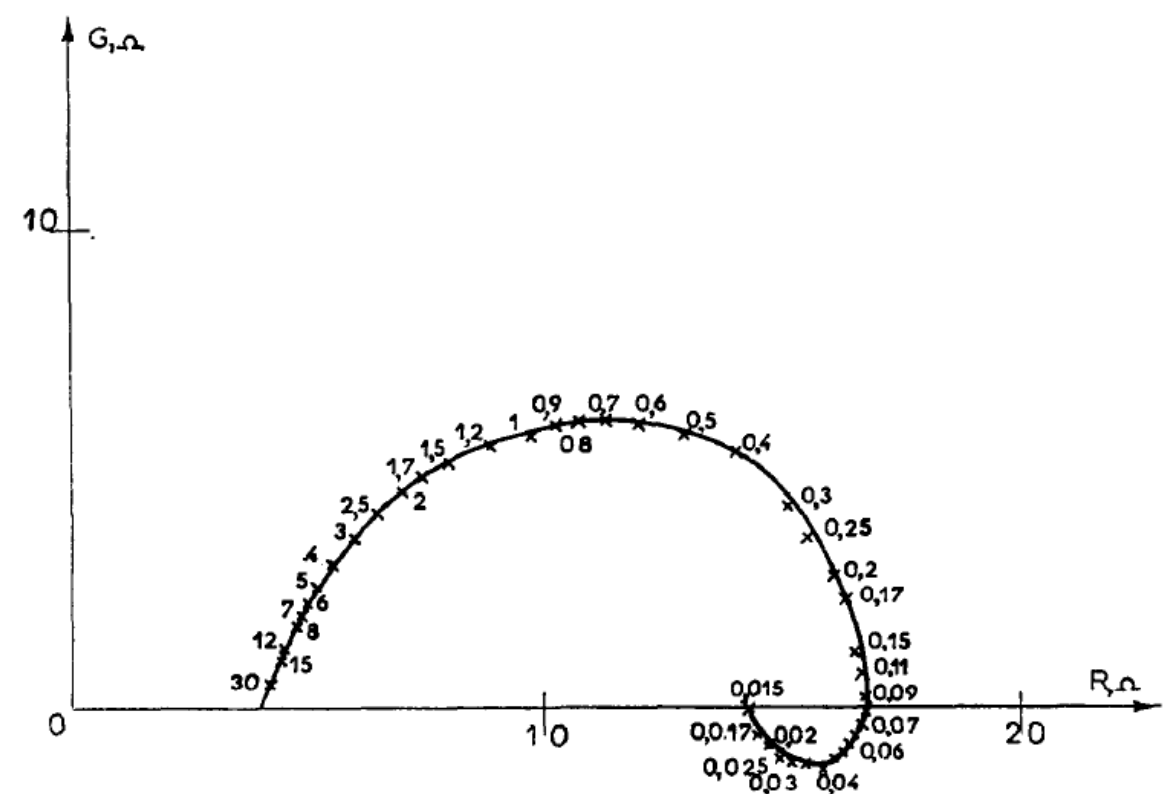

Figure 17b 


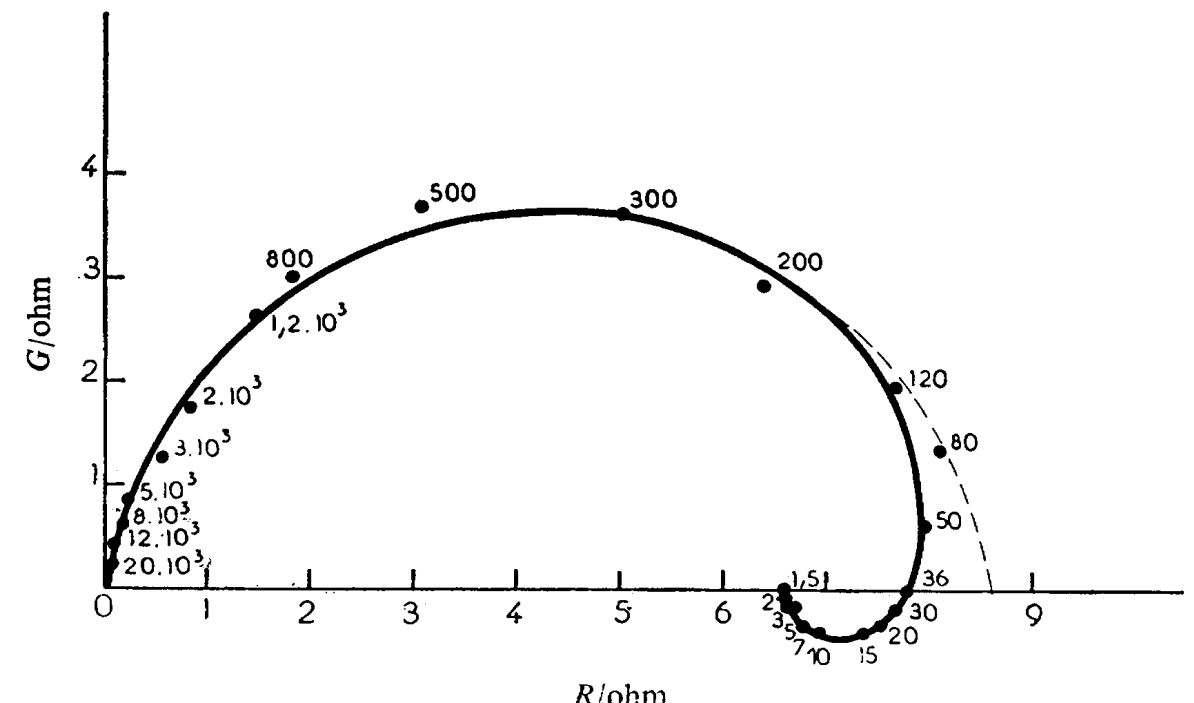

(a)

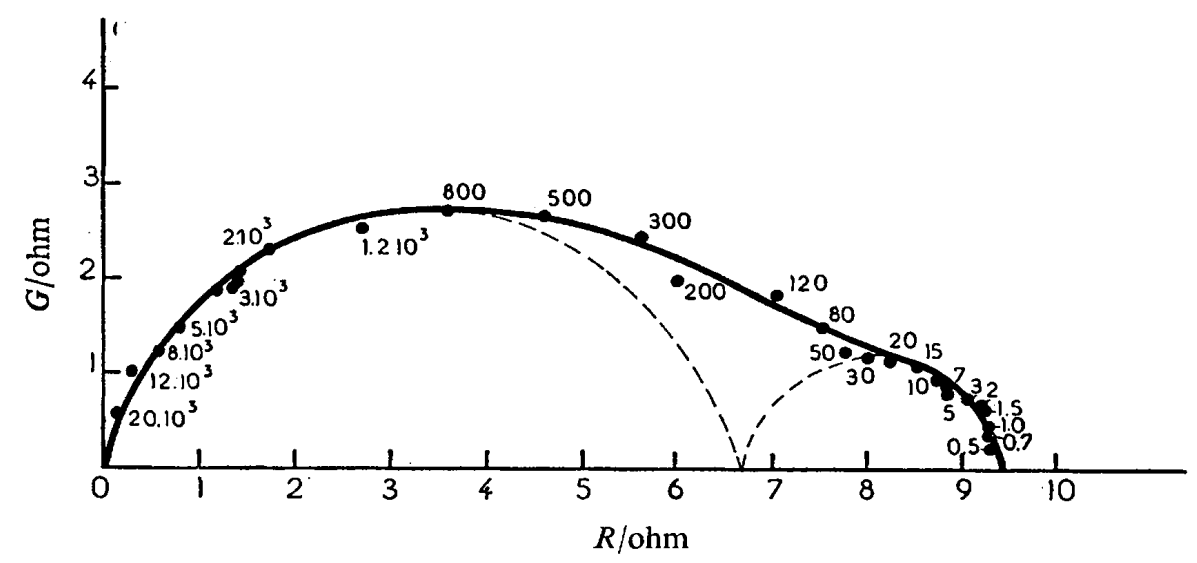

Figure 18a 


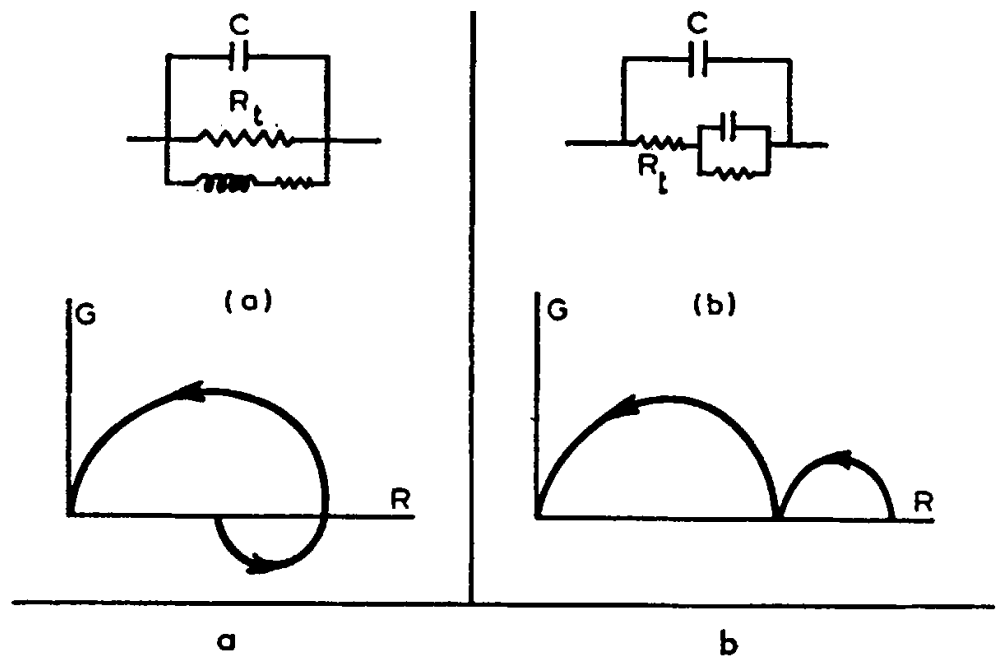

Figure $18 b$ 


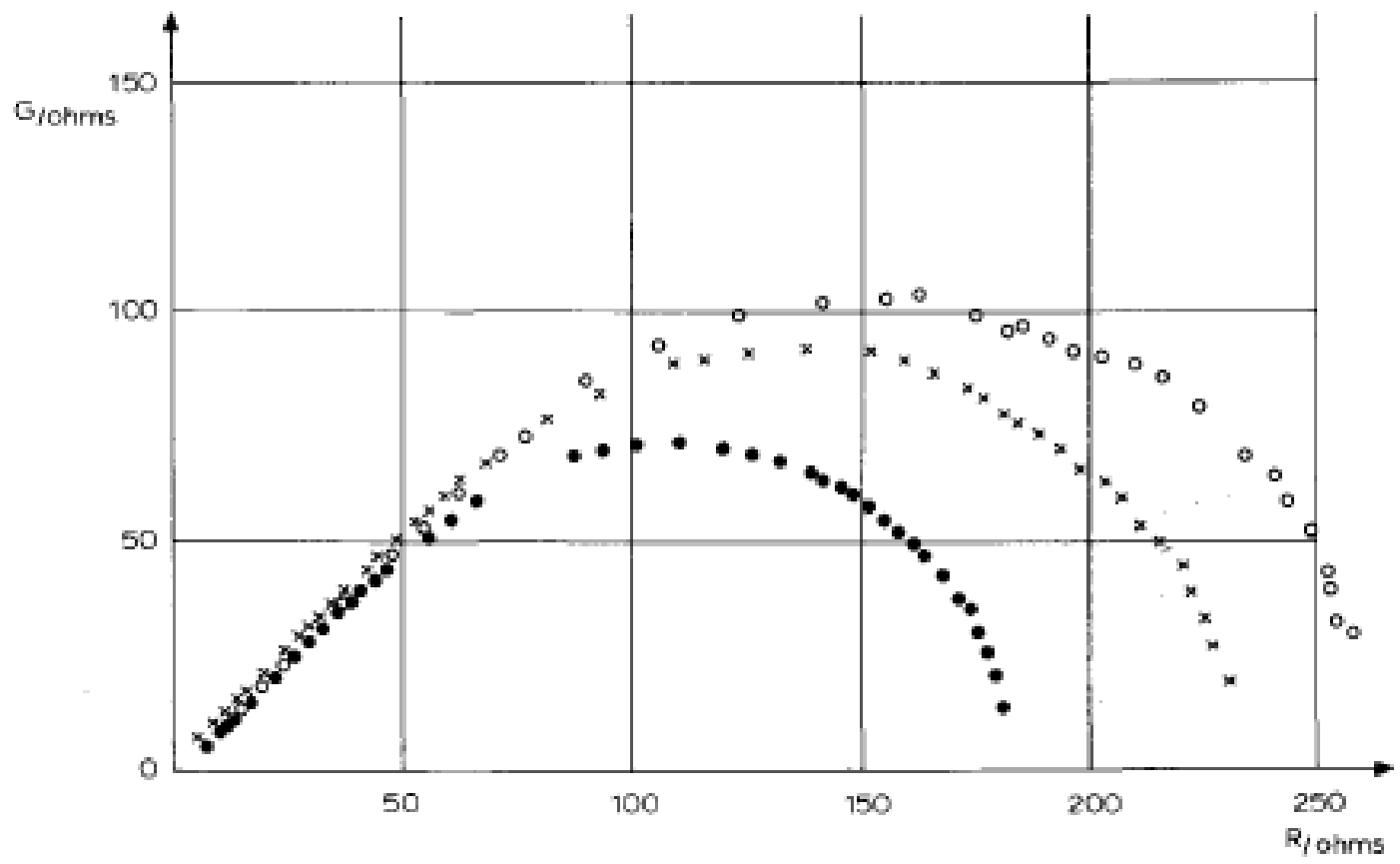

Figure 19 


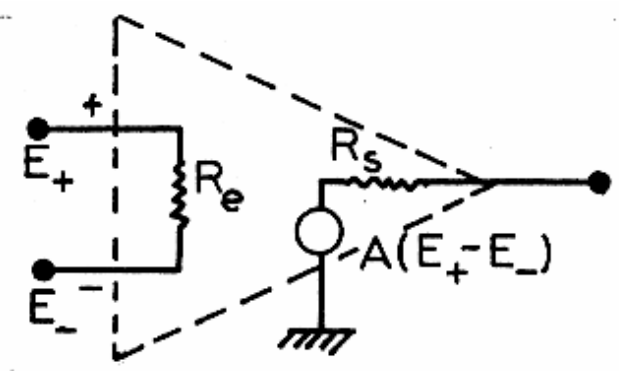

Figure 20a 


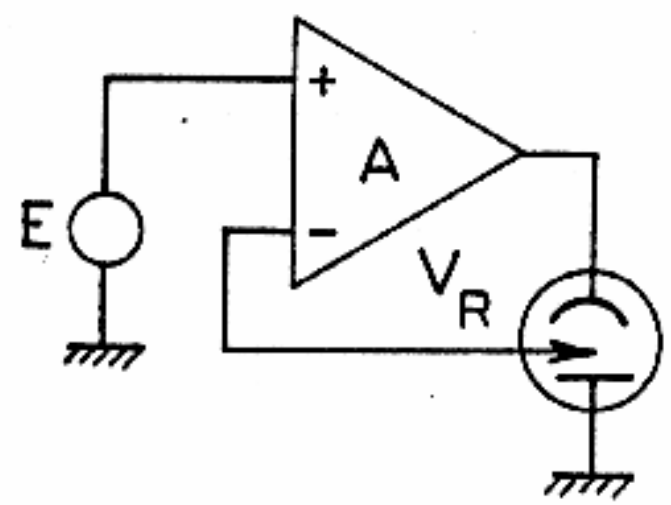

Figure 20b 


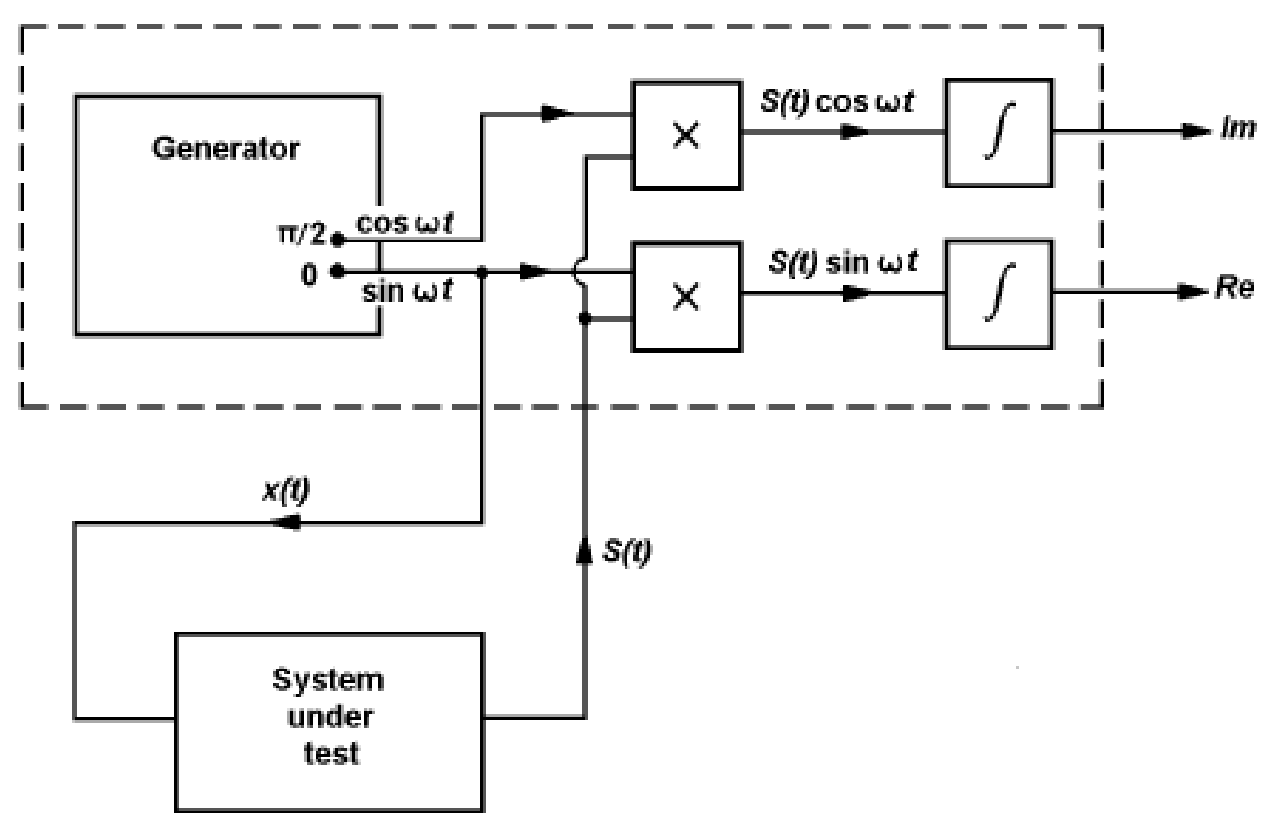

Figure 21a 


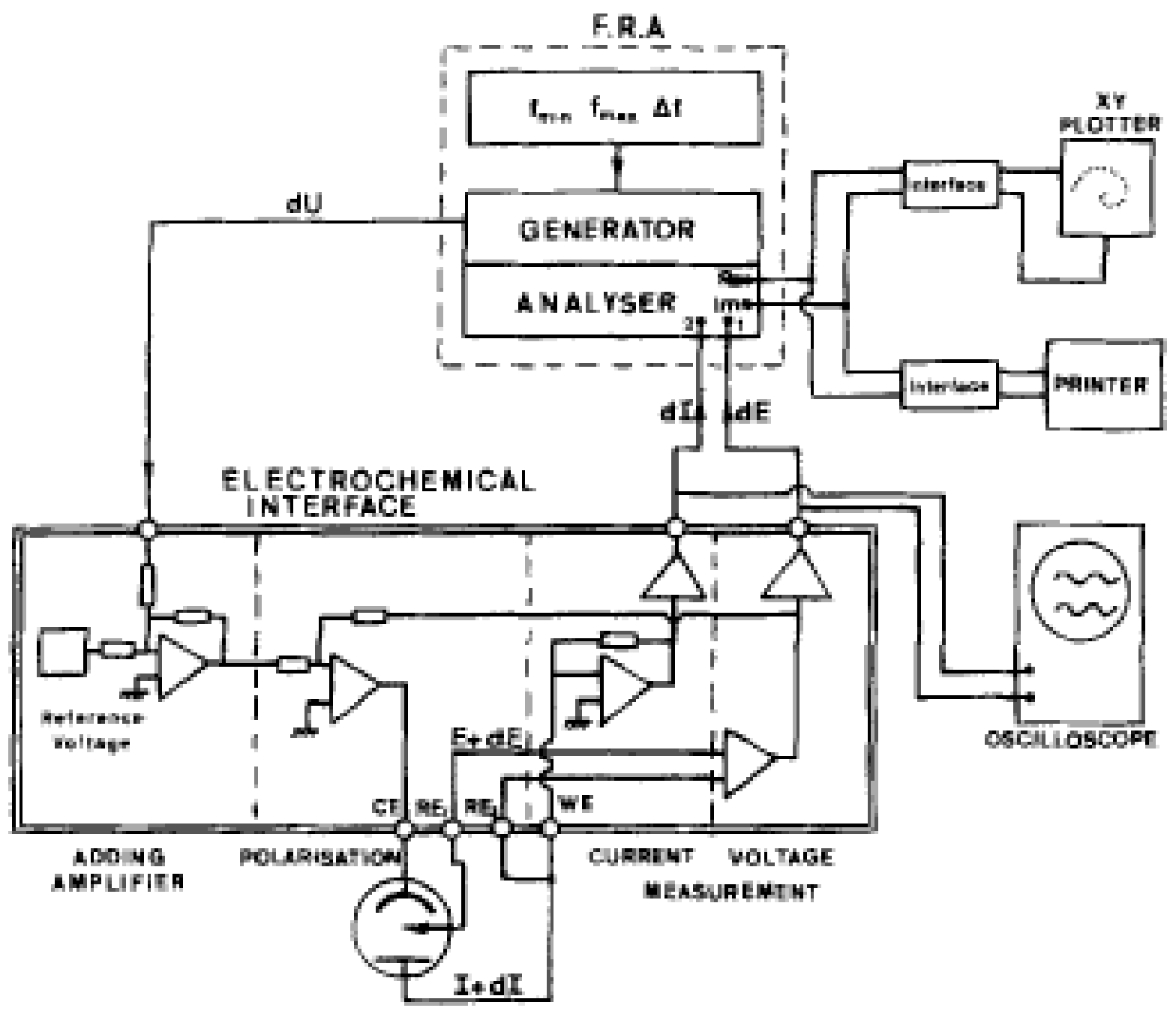

Figure $21 \mathrm{~b}$ 


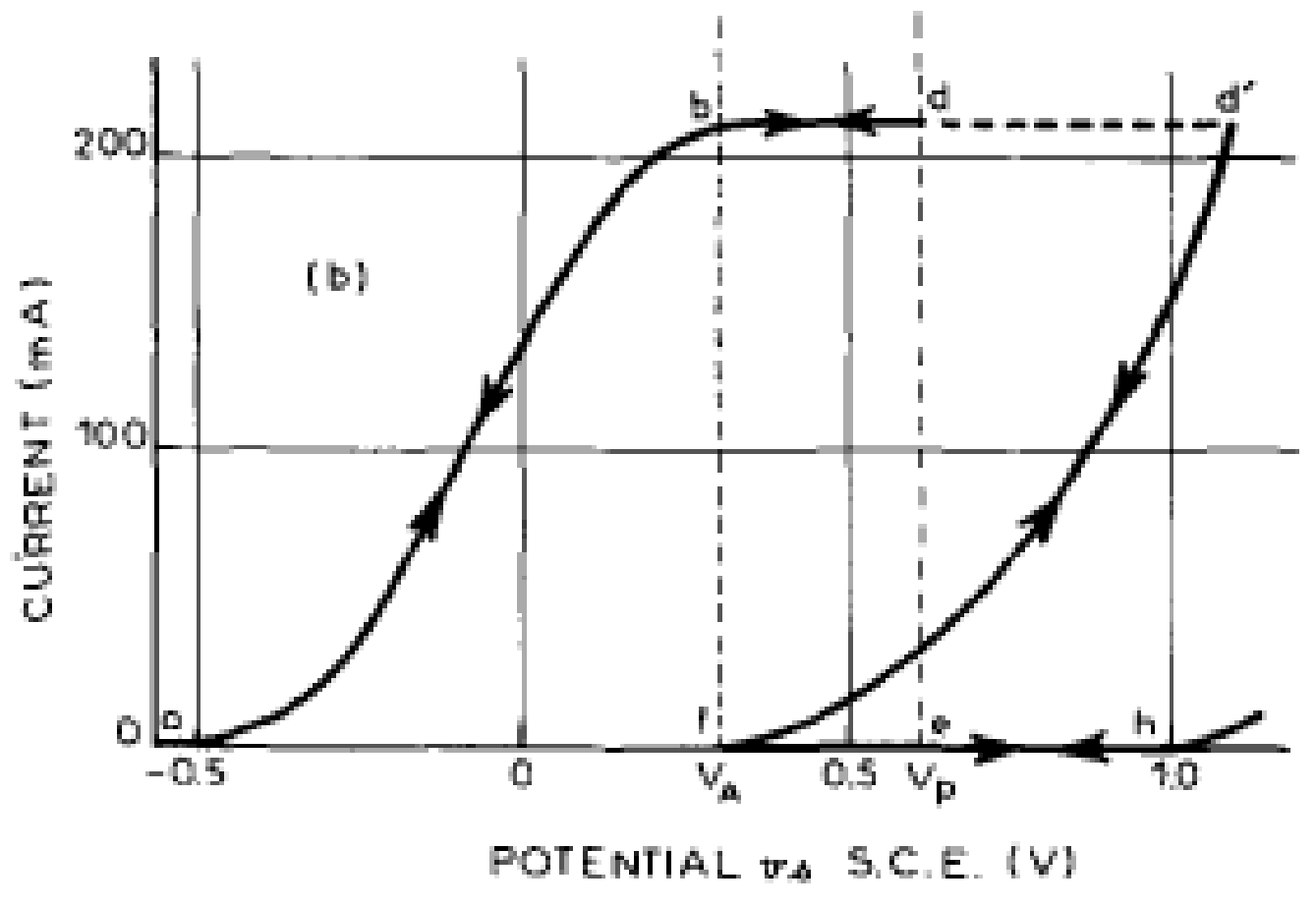

Figure 22a 


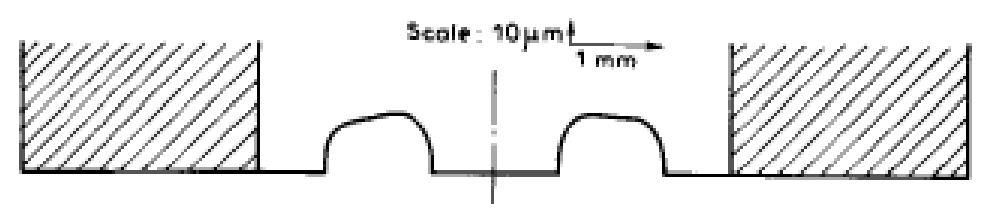

Figure 22b 


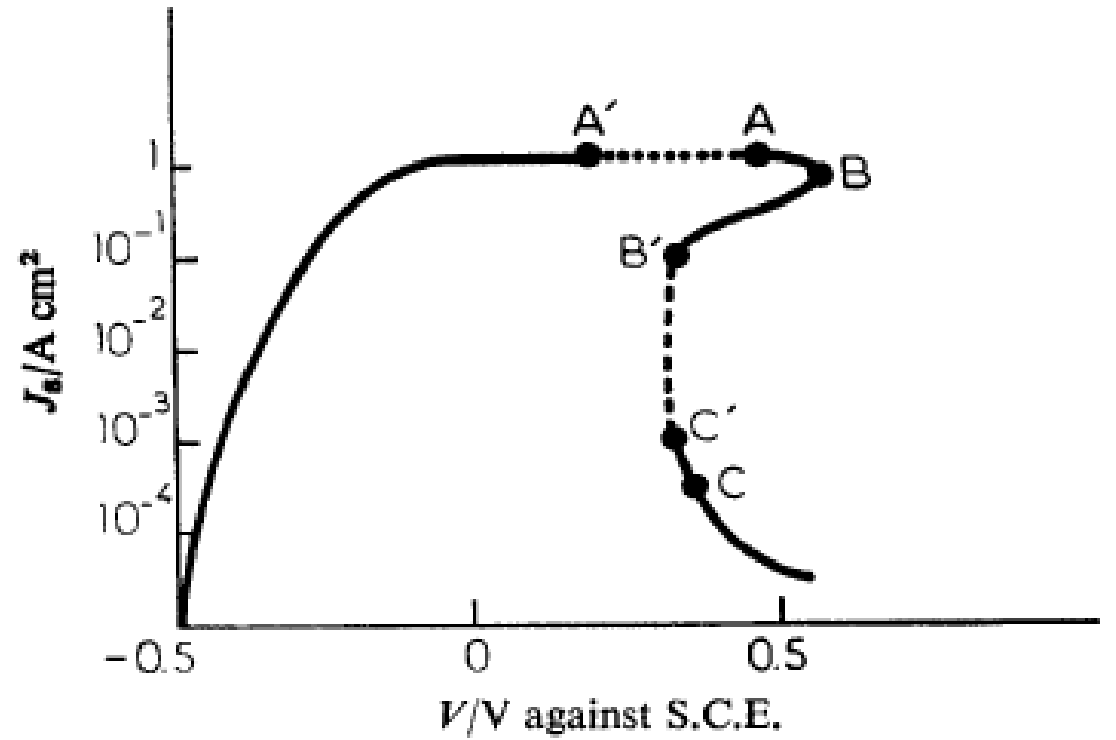

Figure 22c 

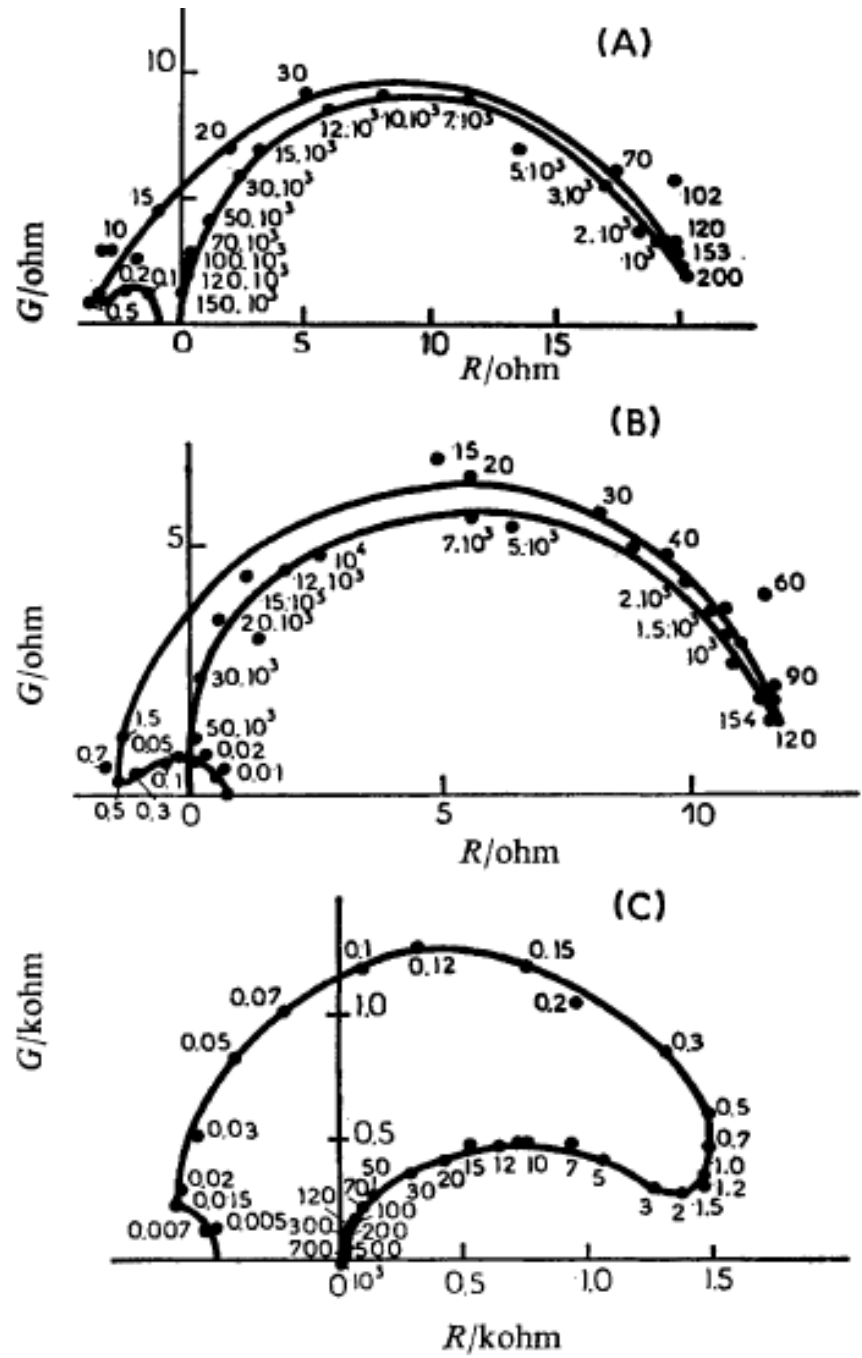

Figure 23 

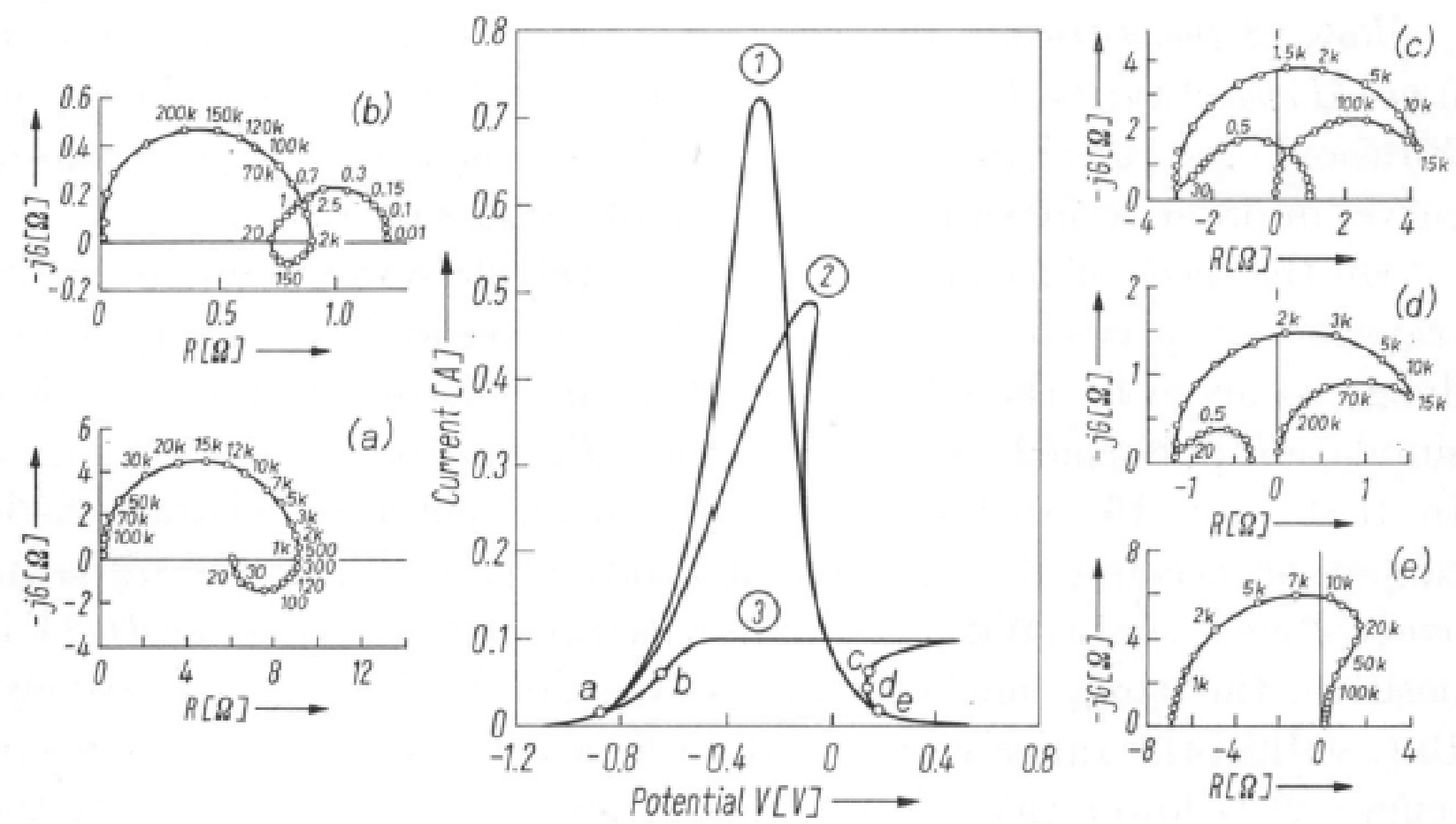

Figure 24 